\title{
Intensive radiosonde observations of the diurnal tide and planetary waves in the lower atmosphere over Yichang $\left(111^{\circ} 18^{\prime} \mathrm{E}, 3^{\circ} 42^{\prime} \mathrm{N}\right)$, China
}

\author{
C. M. Huang ${ }^{1,2,3,4}$, S. D. Zhang ${ }^{1,2,3}$, and F. Yi ${ }^{1,2,3}$ \\ ${ }^{1}$ School of Electronic Information, Wuhan University, Wuhan, Hubei, China \\ ${ }^{2}$ Key Laboratory of Geospace Environment and Geodesy, Ministry of Education, Wuhan, Hubei, China \\ ${ }^{3}$ State Observatory for Atmospheric Remote Sensing, Wuhan, China \\ ${ }^{4}$ State Key Laboratory of Space Weather, Chinese Academy of Sciences, Beijing 100080, China
}

Received: 20 November 2007 - Revised: 5 September 2008 - Accepted: 5 November 2008 - Published: 4 March 2009

\begin{abstract}
The characteristics of diurnal tide and planetary waves (PWs) in the troposphere and lower stratosphere (TLS) over Yichang $\left(111^{\circ} 18^{\prime} \mathrm{E}, 30^{\circ} 42^{\prime} \mathrm{N}\right)$ were studied by using the data from intensive radiosonde observations in $\mathrm{Au}-$ gust 2006 (summer month) and January 2007 (winter month) on an eight-times-daily basis. The radiosonde observations of the diurnal tide and PWs in the TLS in the mid-latitudes have seldom been reported. We find that there exists dominant diurnal oscillations in the TLS over Yichang. The observed diurnal tide consists of significant nonmigrating components, which may be owning to the local latent heat release. Since the nonmigrating tides are usually composed of high order modes with smaller vertical wavelengths, which are prone to dissipation in comparison with the low order modes, the observational tidal amplitudes decrease sharply at several heights. Some evident discrepancies between the observations and the GSWM-02 are found, which may result mainly from the inaccurate prediction of the nonmigrating tidal components by the GSWM-02. And, due to the evident seasonal differences of the water vapor mixing ratio disturbance and the tropospheric jet induced turbulence in winter, the diurnal tides in the summer and winter months have some different characteristics. Besides the diurnal tide, obvious quasi 7-day PW (QSDPW) and quasi 10-day PW (QTDPW) are also recognized from our observations in both the summer and winter months. The QSDPWs in the troposphere in both the summer and winter months show a standing wave structure, while the QTDPWs generally exhibit traveling wave characteristics. Spectral analyses reveal that some waves with periods around that of the diurnal tide
\end{abstract}

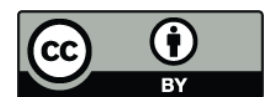

Correspondence to: S. D. Zhang (zsd@whu.edu.cn) are generated due to the interactions of the diurnal tide and PWs and the tidal amplitudes are modulated by the PWs, indicating the extensive coupling between the diurnal tide and PWs. Moreover, our observations manifest that the PWs can exert great impacts on the tropospheric jet in winter and the tropopause in both the summer and winter months.

Keywords. Meteorology and atmospheric dynamics (Middle atmosphere dynamics; Waves and tides; General or miscellaneous)

\section{Introduction}

The atmosphere is frequently disturbed by various kinds of waves, e.g. gravity waves (GWs), tidal waves and planetary waves (PWs), which are believed to impact significantly on local and global atmospheric climatology (Alexander and Pfister, 1995; Alexander, 1998; Batista et al., 2004; Kishore et al., 2004). It is extensively accepted that these atmospheric waves are mainly excited in the lower atmosphere (Forbes and Leveroni, 1992; Smith, 1997; Hagan et al., 2001; Hagan and Forbes, 2002; Fritts and Alexander, 2003; Batista et al., 2004).

Atmospheric tides are global-scale waves with periods that are harmonics of a solar day. By definition, the migrating tides are the subset of tides propagating westward with the apparent motion of the Sun with zonal wavenumbers $s$ equal to their frequencies $n$ in cycles per day while the nonmigrating tides are those with $s \neq n$. Compared with their migrating counterparts, the nonmigrating tides have more local characteristics. The tidal components with frequencies $n=1,2,3, \ldots$ are, respectively, named the diurnal, semidiurnal, terdiurnal tides. Tides are believed to play an important

Published by Copernicus Publications on behalf of the European Geosciences Union. 
role in the large-scale circulation patterns and strongly modulate the propagation conditions experienced by upward propagating GWs. Being one of the most striking features in the mesosphere and lower thermosphere (MLT), where the tidal horizontal wind amplitudes can reach several tens of $\mathrm{ms}^{-1}$, tides in the MLT have been extensively studied over the last three decades (Vincent et al., 1998; Yi, 2001; Manson et al., 2002; Shepherd and Fricke-Begemann, 2004; Zhang et al., 2004). While, for tides in the troposphere and lower stratosphere (TLS), possibly due to their weak amplitudes, they have not been subjected to adequate study. However, it is well known that the primary sources of tides are located in the TLS, especially those of the nonmigrating tides. To further explain the structure and underlying physical mechanisms of tides, we should pay more attention to tides in the TLS.

PWs are oscillations of predominantly tropospheric origin with typical periods of about 2-30 days in the atmosphere (Vincent, 1990). It has been confirmed that PWs extensively exist in the TLS, mesosphere and ionosphere (Hirota and Hirooka, 1984; Hirooka and Hirota, 1985; Randel 1987; Forbes and Leveroni, 1992; Williams and Avery, 1992; Tsuda et al., 1994a; Smith, 1997; Lawrence and Jarvis, 2003; Kishore et al., 2004), and contribute significantly to the variability of atmospheric parameters in these regions. Some literature (Tsuda et al., 1994a; Lawrence and Jarvis, 2003; Lu et al., 2005) has revealed that PWs in the TLS have significant wind amplitudes $\left(>10 \mathrm{~ms}^{-1}\right)$. And, it was suggested that the PWs in the mesosphere and ionosphere were the result of upward propagating PWs in the TLS (Forbes and Leveroni, 1992; Williams and Avery, 1992; Smith, 1997). Therefore, the studies on PWs in the TLS deserve more efforts.

The radiosonde observations contributed greatly to our understanding of dynamics in the TLS (Tsuda et al., 1994a, b, 1997; Allen and Vincent, 1995; Shimizu and Tsuda, 1997; Pfenninger et al., 1999; Vincent and Alexander, 2000; Yoshiki and Sato, 2000; Zink and Vincent, 2001a, b; Innis et al., 2004; Wang et al., 2005; Zhang and Yi, 2005, 2007; Zhang et al., 2006, 2008, 2009) because of their excellent height resolution (several tens to hundreds of meters), relatively complete physical quantities, broad geographical coverage and long-term data accumulation. In most of the above cited studies, the adopted data came mainly from the routine measurements on a twice-daily basis made by meteorology stations. It is noteworthy that since the temporal intervals of the twice daily routine radiosonde measurements are typically $12 \mathrm{~h}$, the diurnal tide in the TLS and its coupling with the PWs can not be revealed by these observations. Recently, data from intensive radiosonde observations were used to study the lower atmospheric structures and waves (Tsuda et al., 1994a, b; Seidel et al., 2005; Zhang et al., 2008, 2009), including the diurnal tide and PWs, but these observations are generally sparse. Moreover, most of the previous radiosonde observations concentrated on the properties of inertial GWs in the TLS. Tsuda et al. (1994a) and Shimizu and
Tsuda (1997) have studied the equatorial waves and diurnal tide by using radiosonde observations in the equatorial regions. Most recently, Innis et al. (2004) investigated the PW modulation of GW over Antarctica by using the data from multi-station radiosonde observations. However, the properties of the tides and PWs in the TLS over mid-latitudes have seldom been reported. Therefore, more radiosonde observations with shorter time intervals in mid-latitudes are needed.

Aiming at further investigating the lower atmospheric dynamics, especially the lower atmospheric waves and their interactions, a two-month (August 2006 and January 2007) radiosonde observation campaign was launched by Wuhan University. In this campaign, the radiosonde observations were made at Yichang $\left(111^{\circ} 18^{\prime} \mathrm{E}, 30^{\circ} 42^{\prime} \mathrm{N}\right)$ on an eighttimes-daily basis. Compared with the routine radiosonde observation (based on twice daily measurements) made by meteorological agencies, the data from this campaign have a shorter time interval, which permits us to study the properties of diurnal tide and its coupling with PWs.

In the presented paper, we focus primarily on the diurnal tide and PWs in the TLS. The data set utilized in this paper is described in detail in the following section. The results of the diurnal tide and PWs are given, respectively, in Sects. 3 and 4 . The coupling between the tide and PWs is discussed in Sect. 5. In Sect. 6, the possible impacts of the PWs on the tropospheric jet and tropopause are investigated. In the last section, we give a brief summary of our observations.

\section{Data description}

The data utilized in this paper are for radiosonde observational campaigns conducted by Wuhan University during one-month periods in each of August 2006 and January 2007. In these campaigns, the L-band radiosondes were used and the observations were made at Yichang $\left(111^{\circ} 18^{\prime} \mathrm{E}\right.$, $30^{\circ} 42^{\prime} \mathrm{N}$ ) on an eight-times-daily basis at 01:00, 04:00, 07:00, 10:00, 13:00, 16:00, 19:00 and 22:00 LT. In each measurement by radiosonde, meteorological variables such as pressure, temperature and relative humidity are measured. The horizontal winds can be attained by tracking the position of the balloon by the L-band radar. The raw data are sampled at a 1-2 s interval, resulting in an uneven height resolution, which varies from several to tens of meters. For convenience, in this paper, the raw data was processed to have an even height resolution $(50 \mathrm{~m})$ by applying a linear interpolation to temperature, pressure and the relative humidity data and a cubicspline interpolation to the wind measurements. The resolutions of the temperature, pressure, relative humidity data are, respectively, $\pm 0.1 \mathrm{~K}, \pm 0.1 \mathrm{hPa}, \pm 1 \%$ and those of the wind data are about $0.5 \mathrm{~ms}^{-1}$. After the temperature correction, the accuracy of the relative humidity data is close to that of a Vaisala RS80 radiosonde. The quality of the utilized data in this paper has been checked using objective and subjective techniques by Yichang Meteorological Bureau. 

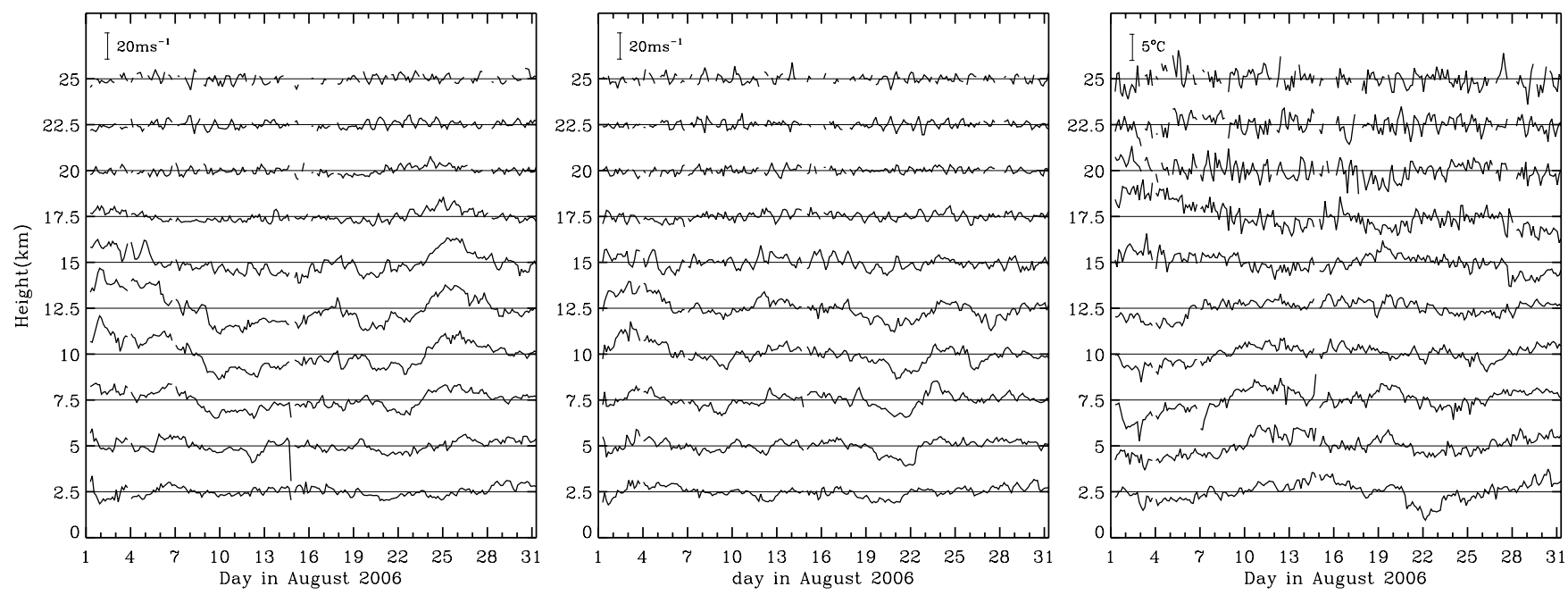

Fig. 1. The raw time series for the zonal wind (left), meridional wind (middle) and temperature (right) disturbances at every $2.5 \mathrm{~km}$ in August 2006.
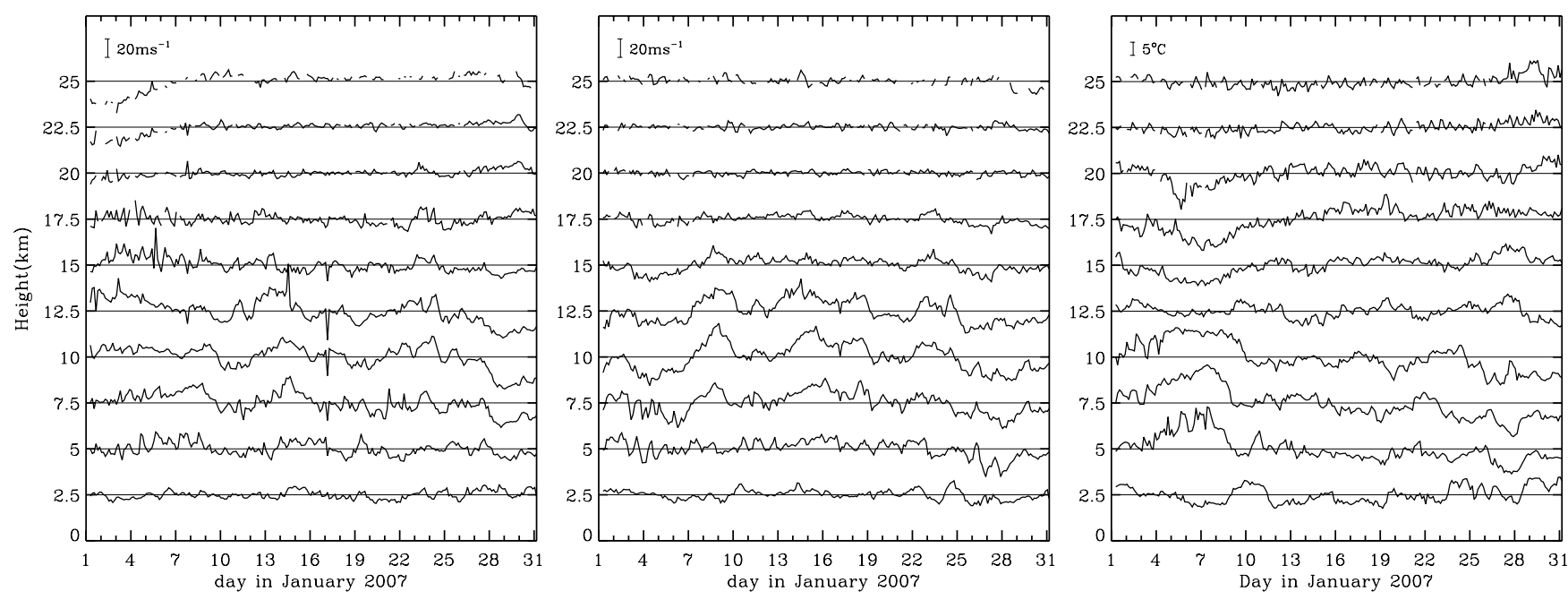

Fig. 2. Similar to Fig. 1, but in January 2007.

The adopted data set consists of 241 measurements in August 2006 and 240 measurements in January 2007. The typical height coverage of the radiosonde observation is from the surface up to about $25-40 \mathrm{~km}$, and the uncertainty of the upper height is due to the variable burst height of the balloon. In our data set, over $70 \%$ of measurements can reach $25 \mathrm{~km}$, thus $25 \mathrm{~km}$ is chosen as the upper height limit of our analysis. Figures 1 and 2 present the raw time series for the zonal wind, meridional wind and the temperature disturbances (subtracting the monthly-averaged background) at every $2.5 \mathrm{~km}$. From these figures, we can see that the three physical quantities are obviously disturbed by many waves with different periods.

Subsequently, we would like to provide the monthlyaveraged zonal wind, meridional wind and temperature at each altitude in these two months in Fig. 3. The characteristics of the background atmosphere over Yichang in Summer and Winter can be summarized as follows: the monthly-averaged temperature has an extremely low value $-73.4^{\circ} \mathrm{C}$ around $16.95 \mathrm{~km}$ for August 2006 and $-68.4^{\circ} \mathrm{C}$ around $17.9 \mathrm{~km}$ for January 2007, displaying a marked cold point tropopause, which is identified as the altitude at which the temperature is minimum; there exists an evident tropospheric jet $\left(58.2 \mathrm{~ms}^{-1}\right.$ at $\left.11.65 \mathrm{~km}\right)$ in the winter month and does not exist in the summer month. 

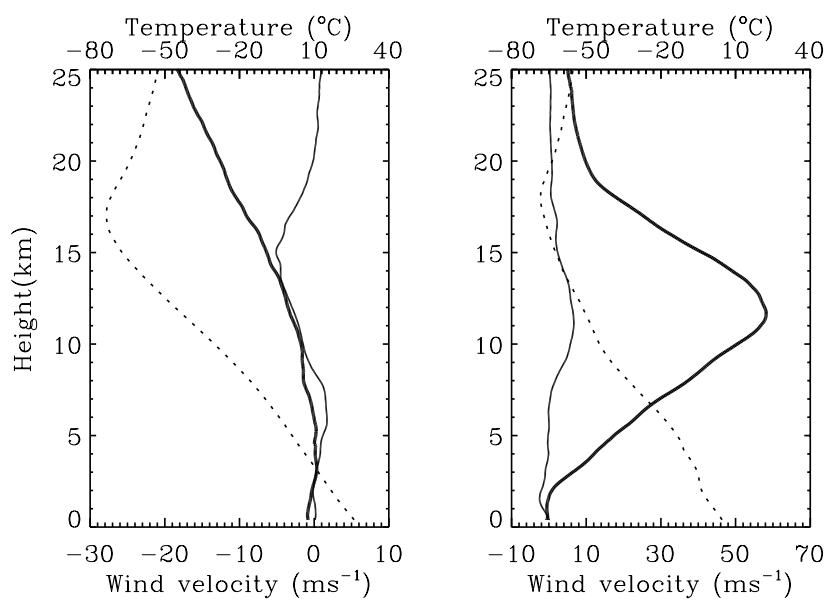

Fig. 3. The background zonal wind (thick solid), meridional wind (thin solid) and temperature (dotted) in August 2006 (left) and January 2007 (right).

\section{Diurnal tide}

Our eight-times-daily radiosonde observations provide a 3-h time resolution and allow us to study the diurnal oscillation in the temporal domain. To explore the tidal disturbances, we apply a high-pass filter with a cutoff at $36 \mathrm{~h}$ for the time series of the raw data of the zonal wind, meridional wind and the temperature at each height. A Lomb-Scargle periodogram analysis (Scargle, 1982) is performed on the resultant time series. Figures 4 and 5 show the frequency spectra at each sampling height for 241 flights in August 2006 and 240 flights in January 2007, respectively. The top, middle and bottom panels are, respectively, for the zonal wind, meridional wind and temperature, and the spectral magnitudes are their amplitudes. It can be clearly observed from these two figures that there exists dominant diurnal oscillations in the wind and temperature fields. Compared with those in the summer month, the significant values in the zonal and meridional winds in the winter month have a smaller height coverage. Near the tropospheric jet height $(11.65 \mathrm{~km}$, above mentioned), the winds are very weak, which may be attributed to the effect of sampling errors in the region where the balloons are being advected horizontally with high speed. And, in the winter month, scattered significant values can be found around the period of $12 \mathrm{~h}$. Considering that the semidiurnal oscillation is much weaker than the diurnal one and the observational interval is $3 \mathrm{~h}$, we do not discuss it in this paper. It is noteworthy that the spectral analysis results may be contaminated by inertial GWs. However, Zhang and Yi $(2005,2007)$ have revealed that the average intrinsic frequency of GWs are several times that of the local Coriolis frequency (the inertial period is about $23.5 \mathrm{~h}$ at the observational site) in the mid-latitudes, implying that the corresponding periods of GWs are about several hours. Hence, the GWs can almost be excluded from the diurnal oscillation. More-
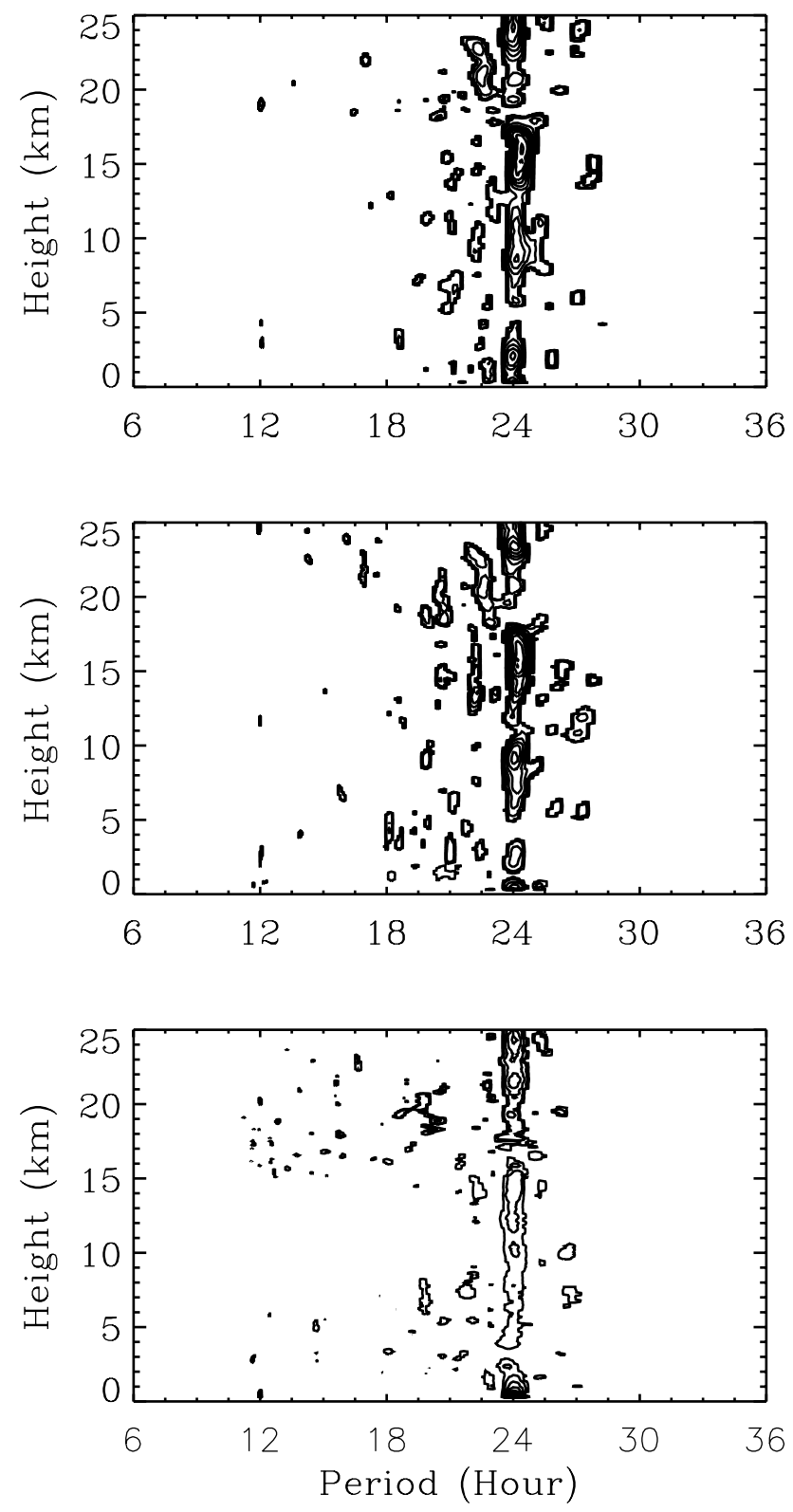

Fig. 4. Lomb-Scargle periodogram of high-pass filtered zonal wind (top), meridional wind (middle), and temperature (bottom) disturbances in August 2006. Only the values with confidence levels greater than $95 \%$ are shown. The minimum values and the intervals of the contours for the zonal wind are all $0.2 \mathrm{~ms}^{-1}$, for the meridional winds are all $0.25 \mathrm{~ms}^{-1}$, and for the temperature are all $0.2 \mathrm{~K}$.

over, GWs, which are believed to be intermittent and random (Fritts and Alexander, 2003), are not always synchronous with local time. They should be smoothed out during the spectral analysis (Tsuda et al., 1994a), since the fitted results are calculated from the consecutive 31-day measurements. A noticeable feature, that can be observed from Figs. 4 and 5, is that there are some significant values scattering around the 
period of $24 \mathrm{~h}$, which may be the symptom of the secondary waves generated by the planetary/tidal wave interaction.

In order to get more information about the diurnal tide, we firstly calculated the monthly-averaged local time variations of the zonal wind, meridional wind and temperature disturbances, and then carry out harmonic fitting on the resultant time series to obtain the monthly-averaged amplitude and phase of the diurnal tide. It should be noted that in this section, only the monthly-averaged characteristics of the diurnal tide is concerned and its day-to-day variation is beyond consideration. The fitted amplitudes and phases of the diurnal tide in August 2006 and January 2007 along with error bars are plotted in Figs. 6 and 7, respectively. For the purpose of comparison, the numerical model results from the Global Scale Wave Model 2000 (GSWM-00) (Hagan et al., 2001) and GSWM-02 (Hagan and Forbes, 2002) are also given in Figs. 6 and 7. The GSWM-00 provides the calculation for migrating tide while the GSWM-02 presents the calculation incorporating the migrating tide and nonmigrating tide associated with tropospheric latent heat processes. Generally speaking, the observational results, both the amplitude and the phase, are closer to the GSWM-02 results, indicating that the nonmigrating diurnal tide has a nonnegligible contribution to the diurnal oscillation over Yichang. In August 2006, the observational amplitudes in three quantities (i.e. zonal wind, meridional wind and temperature) show a basic trend of increasing with height and are greater than those from the models. However, they still display fairly significant height variations, which have been observed by Tsuda et al. (1994a) over Indonesia and explained by the superposition of many tidal wave components. One prominent characteristic regarding the height variations for wind amplitudes, is that at certain altitudes, they decrease sharply. For example, the zonal and meridional winds show an abrupt descending near the tropopause and their amplitudes in the lower stratosphere (19-22 km) are evidently smaller than those in the upper troposphere (14-17 km). In the lower stratosphere, the observed wind amplitude profiles correspond well with the GSWM-02 model while showing clear departure below the tropospause, where the observed amplitudes are evidently larger than the model predictions. The observed temperature amplitudes are clearly larger than the model predictions in the whole height range.

The observed phase profiles in the zonal and meridional winds highly resemble each other. Both of them have a turning point of about $13.5 \mathrm{~km}$. Below (above) this altitude, they exhibit upward (downward) phase progressions, corresponding to downward (upward) wave energy propagations, implying a source is located at this altitude. The wind phase profiles of the GSWM-02 also exhibit such turning points, but the turning points are located at about $8 \mathrm{~km}$, markedly lower than those of the observation result, which may result from the inaccurate prediction of the GSWM-02 for the local latent heat release in the troposphere. It must be recognized that latent heating has significant spatial and temporal
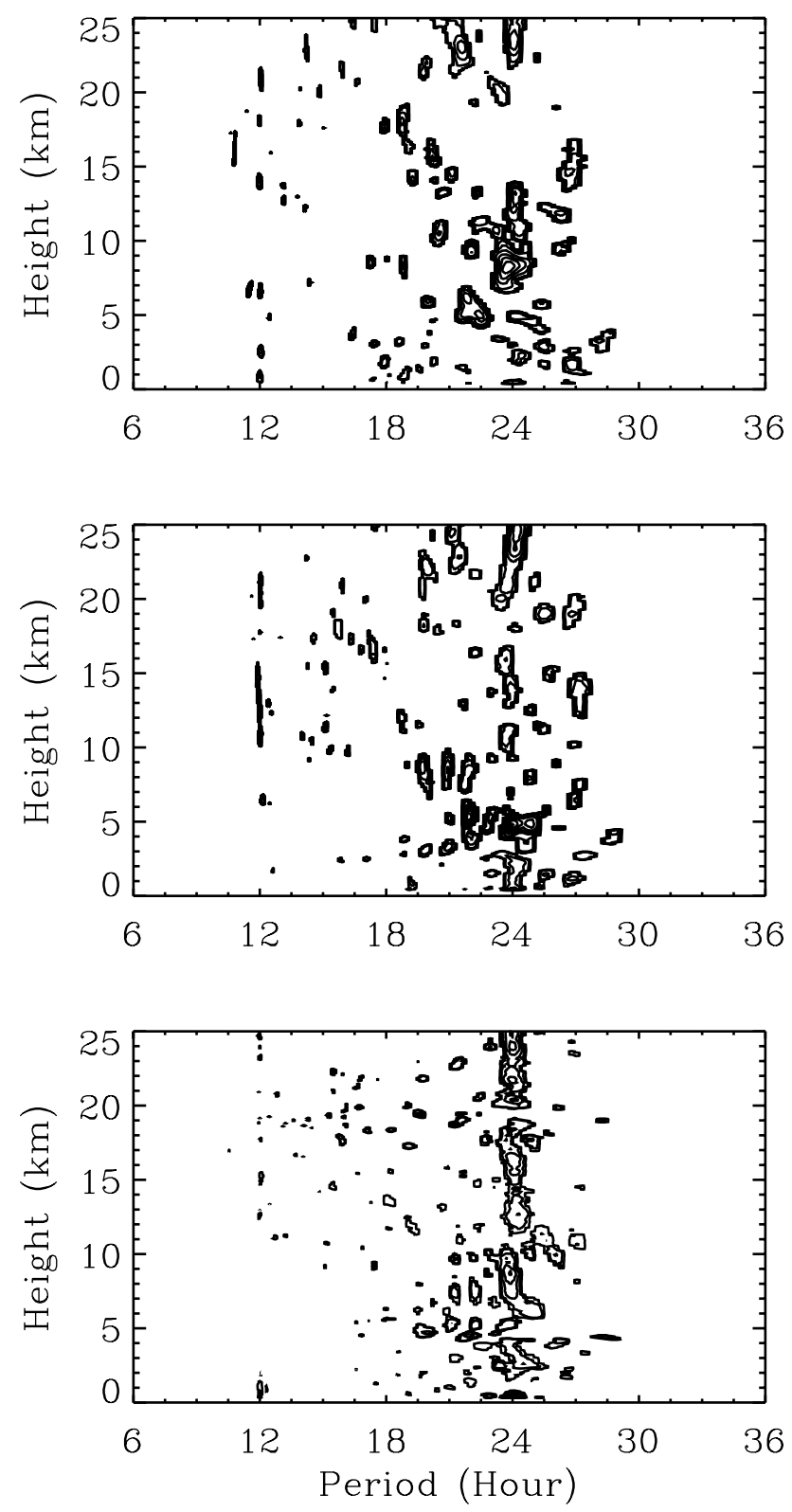

Fig. 5. Similar to Fig. 4, but in January 2007. The minimum values and the intervals of the contours for the zonal and meridional winds are all $0.25 \mathrm{~ms}^{-1}$, and for the temperature are all $0.2 \mathrm{~K}$.

variations and is difficult to estimate exactly. On the whole, the observed wind phases agree well with the GSWM-02 result, indicating the significant nonmigrating diurnal tidal components in the observed diurnal oscillation. In the entire height range, the observed diurnal temperature phase shows a basic tendency of slowly decreasing with height, implying the upward energy propagation and a large vertical wavelength of about $81 \mathrm{~km}$, while the upward propagating diurnal tide from the GSWM-02 is with a vertical wavelength of about $21 \mathrm{~km}$. Additionally, the temperature phase profile 

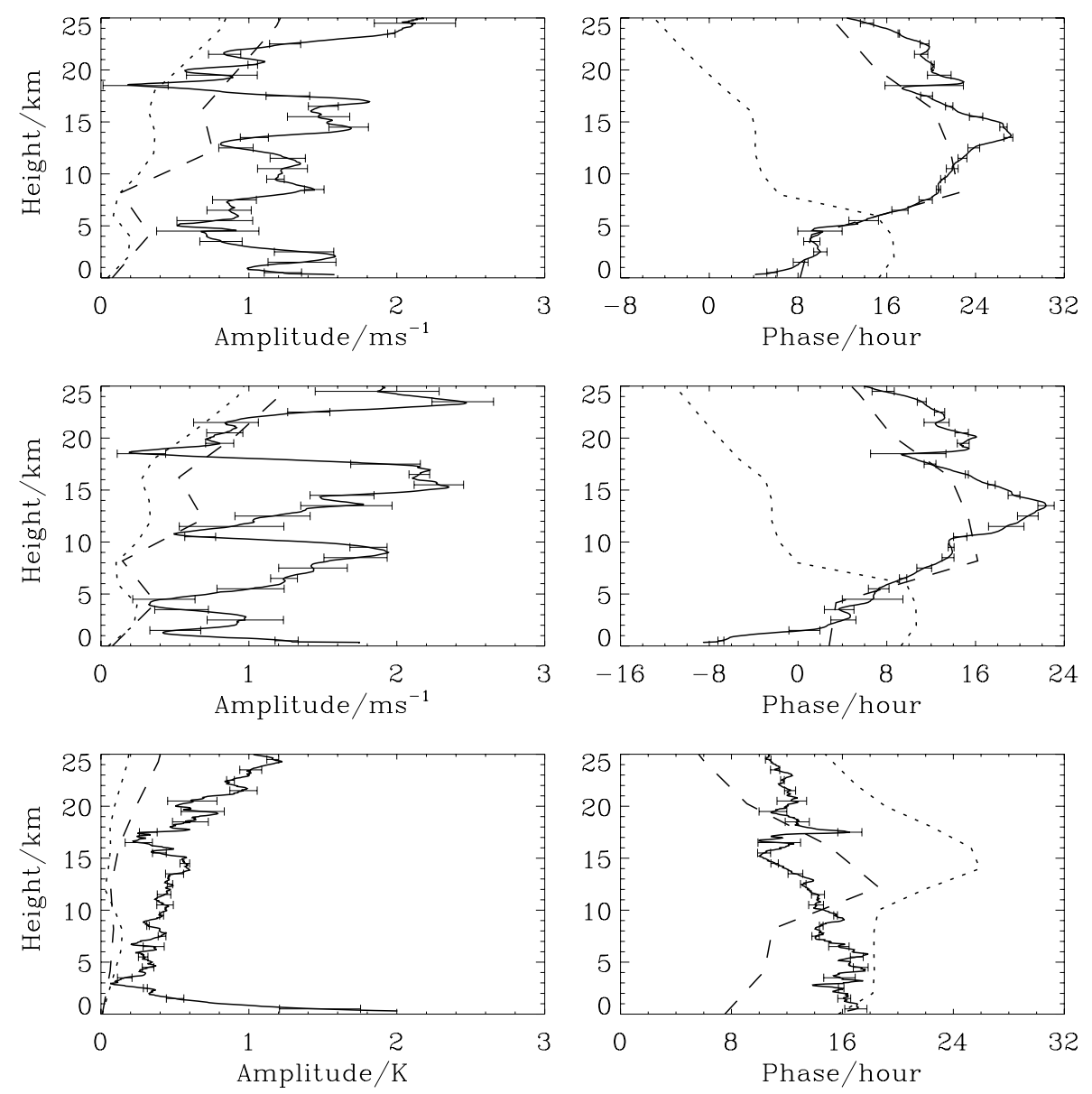

Fig. 6. The comparison between the amplitude and phase of the fitted diurnal tide in August 2006 (solid curve along with error bars), and those from the GSWM-00 (dotted) and GSWM-02 (dashed) in zonal wind (top), meridional wind (middle) and temperature (bottom).

also includes fluctuations with the small vertical scales, indicating the superposition of diurnal components with small vertical wavelengths, i.e. the high order modes of the nonmigrating tide. The observed temperature phase generally shows marked discrepancy from the GSWM-02.

Some similar diurnal tidal characteristics can also be observed from Fig. 7, the result for January 2007. Firstly, the amplitudes and phases in the zonal wind, meridional wind and the temperature are closer to GSWM-02 than to GSWM00 . Secondly, the observed zonal wind, meridional wind and the temperature amplitudes also show significant height variations and are generally greater than those of the GSWM02 , and the temperature amplitude displays a general trend of increasing with height. Moreover, the temperature phase fluctuations also indicate small vertical scale tidal components and exhibits a general tendency of slightly decreasing with height in the entire height range and the generally pronounced discrepancy from the GSWM-02.

Except for above mentioned similarities, some seasonal differences can be revealed by comparing Figs. 6 and 7. For the observed zonal and meridional wind amplitudes in Jan- uary 2007, they decrease abruptly around the tropospheric jet height instead of the tropopause height, and the possible reason has been discussed above. On the other hand, the winter wind phase profiles indicate shorter vertical scales, which may be explained by a greater fraction of the high order tidal modes in winter. Since the high order modes are prone to dissipation in comparison with the low order modes, from several kilometers up to about the tropopause, the observed wind amplitudes abruptly decrease. Above about $17 \mathrm{~km}$, the corresponding vertical wavelengths are very short (about $8.5 \mathrm{~km}$ vs. about $30 \mathrm{~km}$ from the GSWM-02), implying high order tidal modes are still dominant in this height range. Generally speaking, the winter wind phase profiles show more irregular variation and greater departure from the GSWM-02 than the summer ones. Moreover, in January 2007, both the zonal and meridional wind phase profiles display evident turning points at about $17 \mathrm{~km}$, which are higher than those in the summer.

Lindzen (1978) and Hong and Wang (1980) individually proposed that latent heat release associated with cloud and/or raindrop formation could be a significant tidal source. Subsequently, Forbes et al. (1997) presented a correlative analysis 

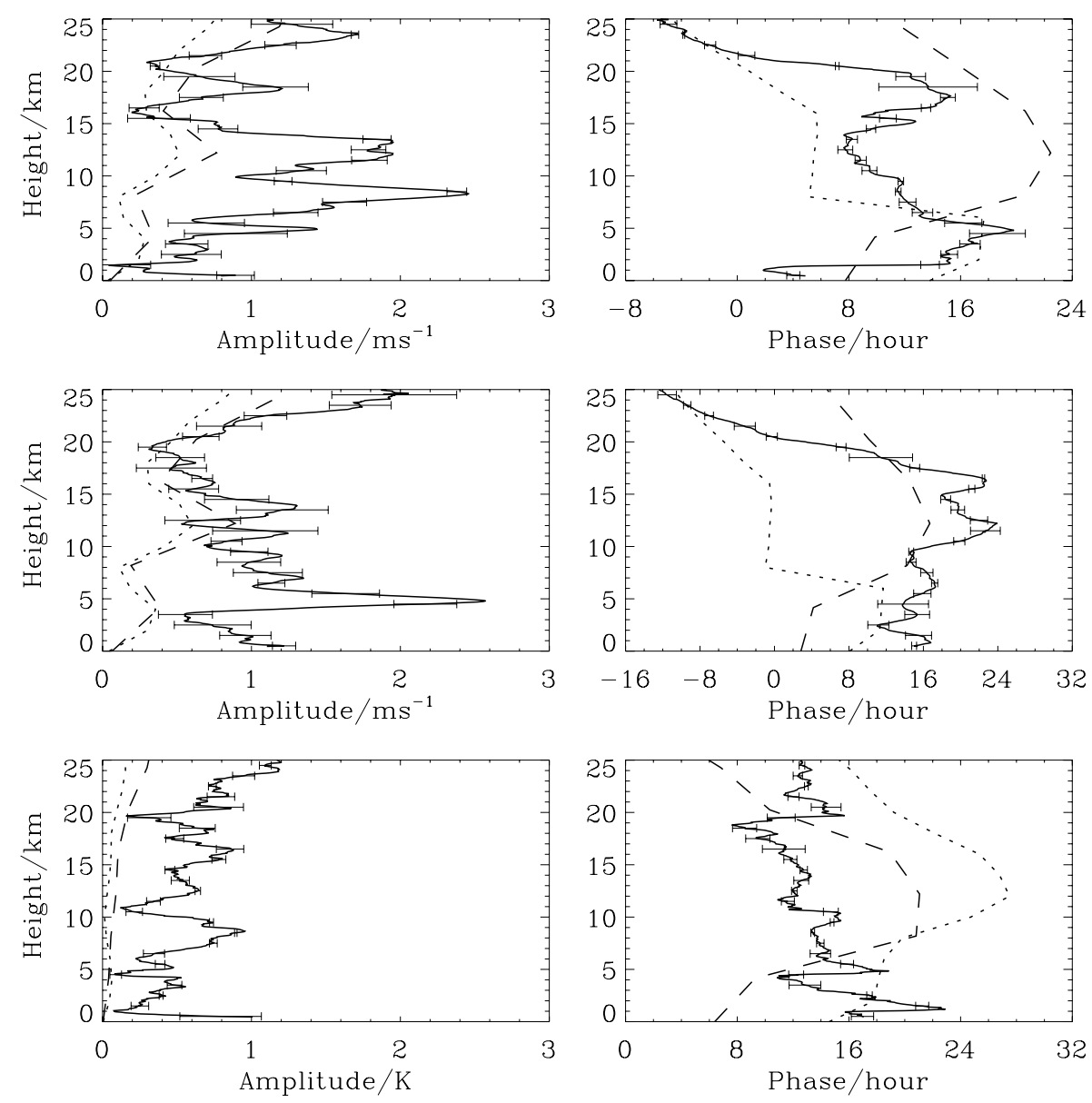

Fig. 7. Similar to Fig. 6, but in January 2007.

on global cloud imagery (GCI) data and rain gauge data to verify that GCI is a viable proxy for rainfall rate. Since the simultaneous GCI data are not accessible to us, we need to acquire some information about the local latent heat release from other data. Tsuda et al. (1994a) have revealed that the large humidity value generally corresponded to the large cloud amount in satellite observations. Thus, it is reasonable for us to take the water vapor mixing ratio from the relative humidity data along with the pressure and temperature as an indicator for the local latent heat release. Here, we provide the monthly-averaged local time variations of the water vapor mixing ratio disturbances in the height range from the surface up to $5 \mathrm{~km}$ in August 2006 and January 2007 (Fig. 8). The water vapor mixing ratio $w$ is obtained from the saturation mixing ratio of water vapor $w_{s}$ and the relative humidity RH expressed as a percent with $w=\frac{\mathrm{RH} \times w_{s}}{100} . w_{s}$ is calculated from the pressure $p$ and the saturation vapor pressure $E$ with $w_{s}=0.622 \frac{E}{p-E}$, and $E$ in $\mathrm{hPa}$ is computed with the Magnus Teten formula $E=6.107 \times 10^{\frac{7.5 T}{T+237.3}}$, where $T$ is the temperature in ${ }^{\circ}$. After getting the water vapor mixing ratio $w$, we calculated the monthly averaged values $\bar{w}$ at each height, which ranges from $189 \times 10^{-4}\left(37 \times 10^{-4}\right)$ near the surface to $41 \times 10^{-4}\left(8 \times 10^{-4}\right)$ at $5 \mathrm{~km}$ in the summer (winter) month. Subsequently, we calculated the monthlyaveraged local time variations of the water vapor mixing ratio at each height $w_{l t}$. For clarifying the diurnal oscillation of the water vapor mixing ratio, we subtract $\bar{w}$ from $w_{l t}$ to get the monthly averaged local time variation of the water vapor mixing ratio disturbance $w_{l t}^{\prime}=w_{l t}-\bar{w}$. Obviously, in both months, the water vapor mixing ratio disturbances display significant diurnal variations below $1 \mathrm{~km}$. They oscillate between $-22 \times 10^{-4}-15 \times 10^{-4}\left(-5 \times 10^{-4}-4 \times 10^{-4}\right)$ in the summer (winter) month, indicating very large diurnal variations of the water vapor mixing ratio. And, the minima appear at about 16:00 LT, corresponding exactly to the maxima of the diurnal temperature oscillation below $1 \mathrm{~km}$ (referring to the diurnal temperature phases shown in Figs. 6 and 7). These reveal that latent heat release is indeed an important source of the above presented diurnal tide. Such a heat source is localized in their horizontal extent. So, it may excite a nonmigrating tide rather than a global tide. Hence, we can observe the great fraction of the nonmigrating diurnal tidal components in Figs. 6 and 7. On the other hand, the water 

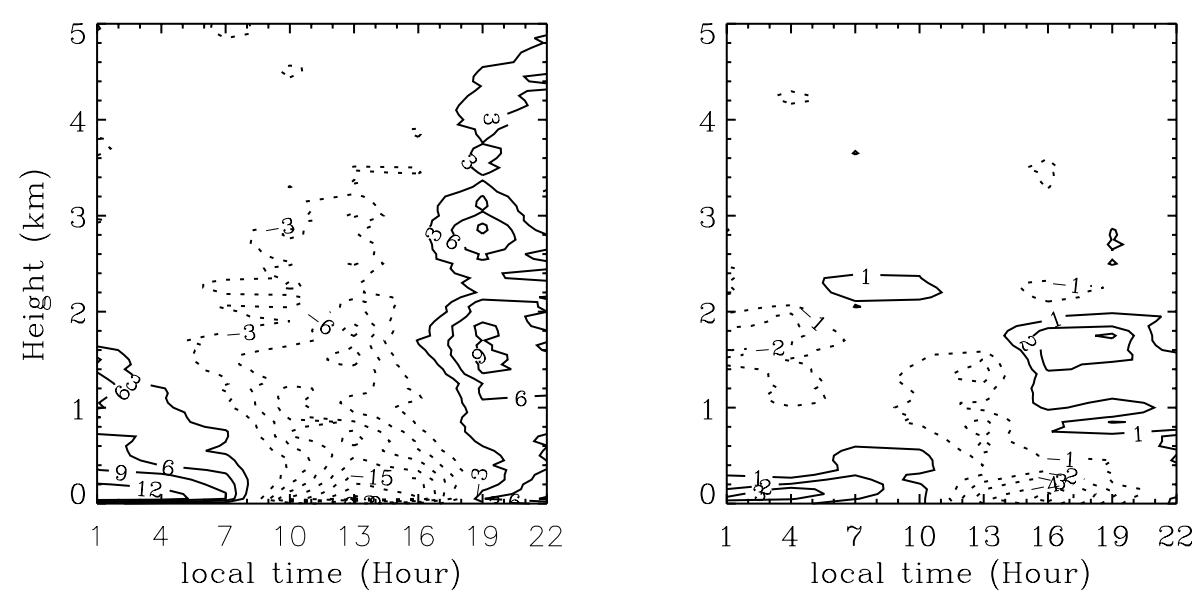

Fig. 8. Monthly-averaged local time variations of the water vapor mixing ratio disturbances in the height range from the surface up to $5 \mathrm{~km}$ in August 2006 (left) and January 2007 (right). The solid and dotted curves denote the positive and negative values, respectively. The minimum positive values and the intervals of the contours are $3 \times 10^{-4}$ in August 2006 and $1 \times 10^{-4}$ in January 2007.

vapor mixing ratio disturbance shows evident season differences. In summer, it is significantly greater than in winter. The diurnal tidal difference between August 2006 and January 2007 may be partly ascribed to the seasonal variation of the latent heat release.

\section{PWs}

In this section, we would like to investigate the PWs. To identify the PW signatures, we detrend the raw time series at each height by subtracting a linear background and perform a Lomb-Scargle periodogram analysis on the resultant time series. Figures 9 and 10 are the frequency spectra for observations in August 2006 and January 2007, respectively, and the spectral magnitudes are wave amplitudes. Since oscillations with periods greater than 20 days are conventionally not classified as PWs because their periods do not conform to those expected for common Rossby modes (Salby, 1984; Beard et al., 2001), only the oscillations with periods between 2-20 days are presented in Figs. 9 and 10. The top, middle and bottom panels are for the zonal wind, meridional wind and the temperature disturbances, respectively. It can be clearly observed from these two figures that there exists prevailing oscillations with periods of PWs in both summer and winter.

Firstly, we analyze the wave activity in the summer month. The quasi 7-day and quasi 10-day oscillations can be recognized from both the zonal and meridional winds. Henceforth, they are nominated as the quasi 7-day PW (QSDPW) and quasi 10-day PW (QTDPW). However, we can not get more detailed information to identify their modes. Their periods in two-wind components are not exactly equal: in the zonal wind field, the exact periods of the QSDPW and QTDPW are, respectively, 7.5 days and 10.9 days, while in the meridional field, they are, respectively, 6.7 days and 12 days. This is consistent with the result of Luo et al. (2002), in which Luo et al. indicated that when there were relatively strong PWs, their periods for the zonal and meridional components did not coincide exactly, though sometimes they were fairly close. For the zonal wind, the significant amplitudes of the QSDPW and QTDPW, respectively, appear in the height ranges of $12-17 \mathrm{~km}$ and $2-20 \mathrm{~km}$, while for the meridional wind, those all occur in the height range of $2-16 \mathrm{~km}$. The temperature oscillations with PW periods are generally weak, only a QTDPW with an exact period of 10.9 days can be observed around $18 \mathrm{~km}$.

The QSDPW and QTDPW can also be seen in the winter month, but their exact periods, wave amplitudes and height coverage are different from those in the summer month. For the QSDPW (QTDPW) in the zonal wind, the exact period is 8 days (10 days) and the significant amplitudes appear in the height range of $4-10 \mathrm{~km}(2-14 \mathrm{~km})$. While, in the meridional wind, the exact period is 8 days ( 12 days) and the significant amplitudes are located in the height range of $5-15 \mathrm{~km}(8-$ $18 \mathrm{~km}$ ). The planetary scale oscillations in the temperature are slightly stronger than those in the summer month and a QSDPW with an exact period of 8 days can be observed at altitudes of 2-18 km.

With the use of Lomb-Scargle periodogram analysis, there are two problems: statistical dificulties and spectral leakage. The statistical difficulties are not severe if the detected signal is strictly periodic. So, it has little effect on our above investigation. However, the spectral leakage is an inherent limitation to the Lomb-Scargle periodogram analysis for data with a finite length, since it assumes that there is a single stationary sinusoid wave with infinite support. It is well known that PWs exhibit significant fluctuations in amplitude and phase on time scales from a few days to months, and often presents as "bursts" of wave activity at a particular period, that is to say, they are commonly non-stationary in a month. 

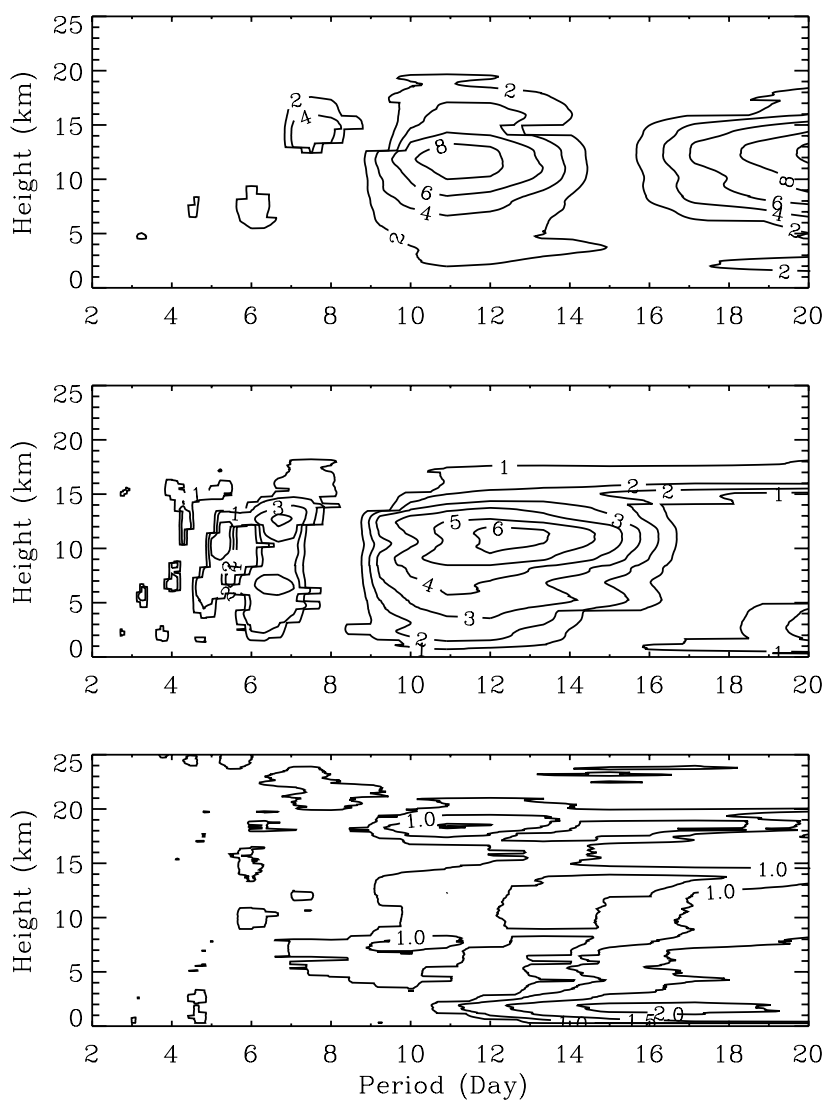

Fig. 9. Lomb-Scargle periodograms of zonal wind (top), meridional wind (middle) and temperature (bottom) disturbances in August 2006. Only the values with confidence levels greater than $95 \%$ are shown. The minimum value and the interval of the contours for the zonal wind are all $2 \mathrm{~ms}^{-1}$, for the meridional wind are all $1 \mathrm{~ms}^{-1}$, and for the temperature are all $0.5 \mathrm{~K}$.

Therefore, a wavelet analysis is applied to further confirm the PW characteristics by determining the dominant oscillations and how those oscillations vary with time. The continuous Morlet wavelet is selected because of its simplicity and resemblance to the PW "packets". The Morlet wavelet consists of a plane wave modulated by a Gaussian:

$\psi(t)=\pi^{-\frac{1}{4}} e^{-i \omega_{0} \frac{(t-\tau)}{s}} e^{-\frac{(t-\tau)^{2}}{2 s^{2}}}$

Where $\tau$ is the time location of the localized transform and $s$ is the scale factor that dilates or contracts the wavelet scale; $\omega_{0}$ is the non-dimensional frequency, here taken to be 6 . By changing the scale $s$ and moving along the time, the normalized local amplitudes of oscillations at selected periods are calculated. In our calculation, the scale parameters are chosen as:

$s_{j}=s_{0} 2^{j \delta_{j}}, j=0,1, \cdots, J$

$J=\delta_{j}^{-1} \log _{2}\left(\frac{N \delta t}{s_{0}}\right)$
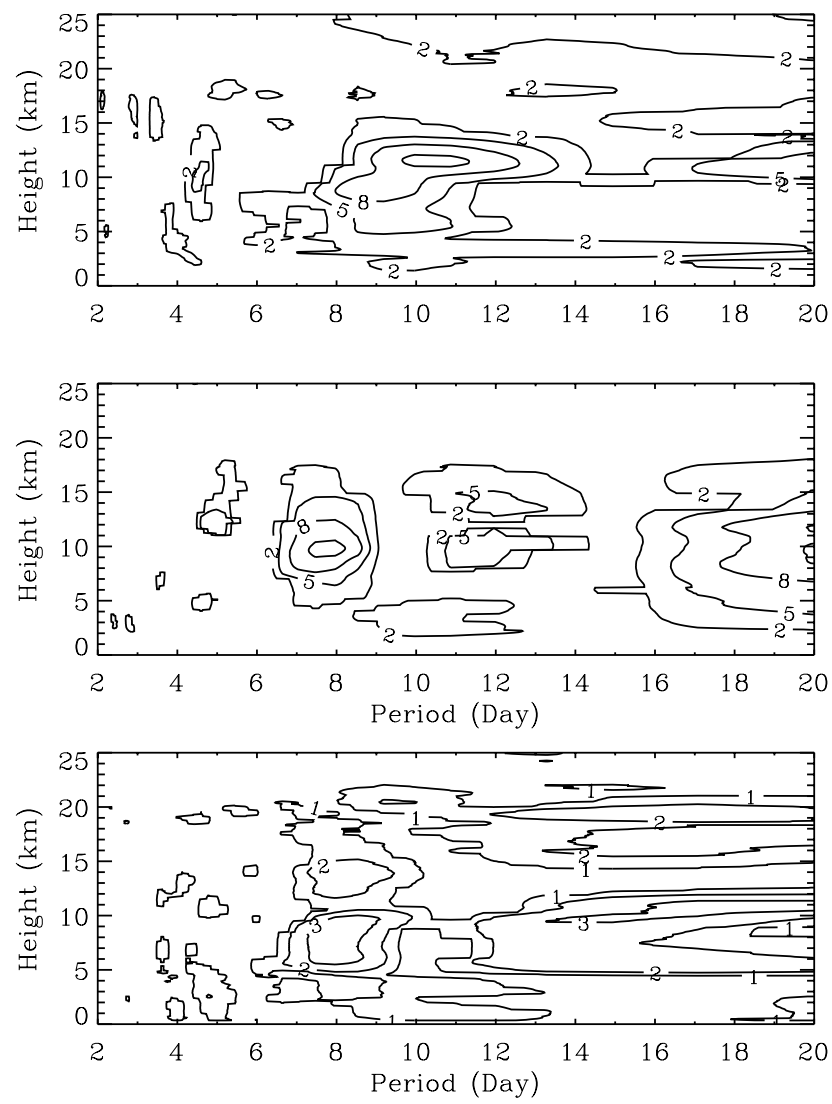

Fig. 10. Similar to Fig. 9, but in January 2007. The minimum value and the interval of the contours for the zonal wind are 2 and $3 \mathrm{~ms}^{-1}$, respectively, for the meridional wind are 2 and $3 \mathrm{~ms}^{-1}$, respectively, and for the temperature are all $1 \mathrm{~K}$.

Where $s_{0}$ is the smallest scale equal to $2 \delta t$ ( $6 \mathrm{~h}$ in our case), and $J$ determines the largest scale (27 in our case); $N$ is the total number of points, and $\delta_{j}$ is equal to 0.25 . For the Morlet wavelet with $\omega_{0}=6$, the ratio between the Fouries period and the wavelet scale is 1.03 .

Since the PW oscillations are not very strong in the temperature field, the wavelet analysis is only fulfiled on the zonal and meridional wind components. The wavelet spectra (figures not presented here) show that: in the period range of 4-16 days and height range of 5-15 km, the periods of the dominant oscillations in the zonal and meridional winds in these two months vary among 6.7 days $\left(s_{19}\right), 8.0$ days $\left(s_{20}\right)$, 9.5 days $\left(s_{21}\right)$ and 11.3 days $\left(s_{22}\right)$ with height and time. Here, we regard the oscillations with the periods of 6.7 days and 8.0 days (9.5 days and 11.3 days) as the QSDPW (QTDPW), and take the average value of the normalized local amplitudes at $s_{19}$ and $s_{20}\left(s_{21}\right.$ and $\left.s_{22}\right)$ as the QSDPW (QTDPW) amplitude. The temporal variations of the QSDPW and QTDPW amplitudes are provided in Figs. 11 and 12. Considering the edge effects due to finite-length time series, i.e. the amplitudes near the edges are underestimated by the adopted 

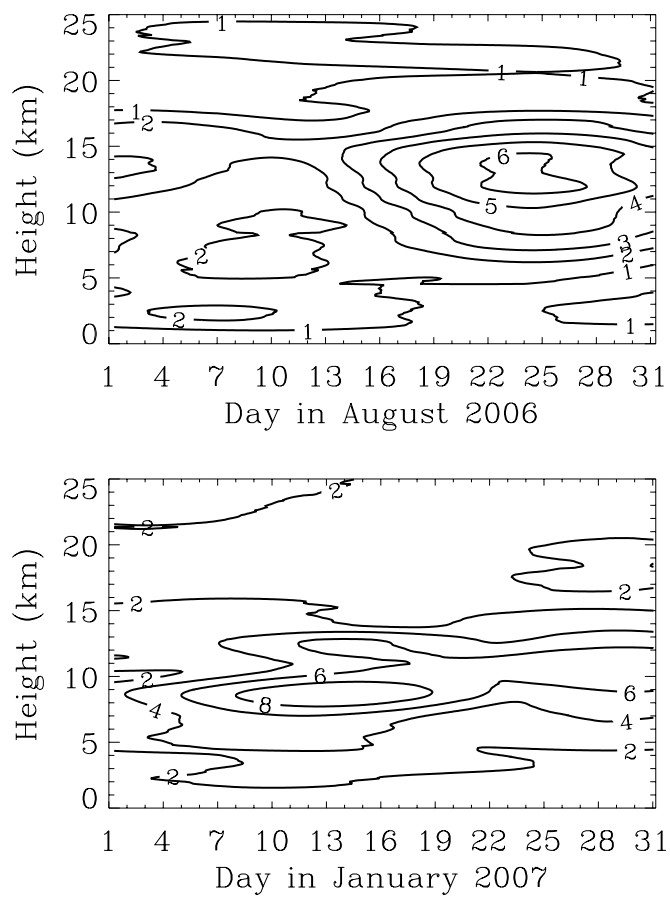
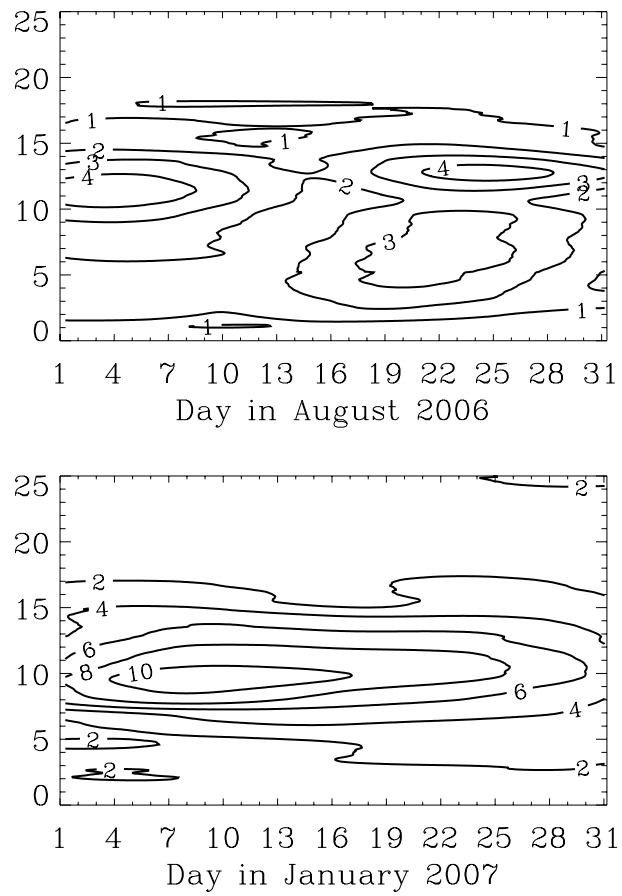

Fig. 11. The QSDPW amplitudes for the zonal wind (left) and meridional wind (right) in August 2006 (upper) and January 2007 (lower) from the wavelet analysis.

wavelet analysis, we can observe from Figs. 11 and 12 that, there indeed exists the remarkable QSDPW and QTDPW oscillations, which is consistent with that deduced from the above Lomb-Scargle periodogram analysis. In January 2007, the QSDPW is strong in the zonal wind from 2 January to 31 January and in the meridional wind from 1 January to 28 January, while in August 2006, its significant zonal component only appears in the second half of the month and its meridional componet is very weak in the middle of the month. As for the QTDPW, the zonal components in August 2006 and January 2007 are both strong during the whole month while the meridional commponent in August 2006 is significant from 1 August to 28 August and that in January 2007 is weak in the middle of January. The zonal and meridional wind amplitudes of the QSDPW and QTDPW in both months exhibit evident fluctuations with height.

To reveal the vetical propagation characteristics of the QSDPW and QTDPW, we employ the harmonic fitting technique to acquire the vertical distributions of their amplitudes and phases. For the time series of the wind disturbances at each altitude $f^{\prime}(t)$, the harmonic fitting formula is:

$f^{\prime}(t)=A \cos \left(\frac{2 \pi}{T} t-\varphi\right)$

where $A, T$ and $\varphi$ are, respectively, the amplitude, period and phase of the planetary wave oscillation. $T$ is chosen according to Figs. 9 and 10: for the QSDPW, it is 7.5 days (6.7 days) for the zonal (meridional) wind in August 2006 and 8 days for the zonal and meridional winds in January 2007; for the QTDPW, it is 10.9 (12) days for the zonal (meridional) wind in August 2006 and 10(12) days for the zonal (meridional) wind in January 2007. Referring to Figs. 11 and 12, we fit the data from 18 August to 31 August (from 2 January to 28 January) to the summer (winter) QSDPW and data from 1 August to 28 August (from 17 January to 31 January) to the summer (winter) QTDPW. The resultant amplitudes and phases of the QSDPW at different altitudes are shown in Fig. 13. It can be observed from Fig. 13 that, the QSDPW amplitudes exhibit evident fluctuations with the height, which conforms with the wavelet analysis result, and the amplitudes in the winter month are distinctly greater than those in the summer month, especially in the meridional component. The summer (winter) zonal wind reaches its maximum $8.1 \mathrm{~ms}^{-1}\left(9.0 \mathrm{~ms}^{-1}\right)$ at $11.9 \mathrm{~km}(8.8 \mathrm{~km})$ while the summer (winter) meridional wind reaches its maximum $6.6 \mathrm{~ms}^{-1}$ $\left(13.1 \mathrm{~ms}^{-1}\right)$ at $12.65 \mathrm{~km}(9.8 \mathrm{~km})$. Obviously, in the summer month, the altitudes where the zonal and meridional winds have significant amplitudes, are evidently higher than those in the winter month. In both seasons and both wind components, the phases near the altitudes where the maximum amplitudes occur are almost constant, indicating there exists a standing PW component. Standing waves are generated by the interference of the incident wave with the reflected wave, which would have the resultant form of $\cos m z \cos (\omega t-\varphi)$, where $m$ is the vertical wave number. The zero or minimum amplitude positions (nodes) and maximum positions 

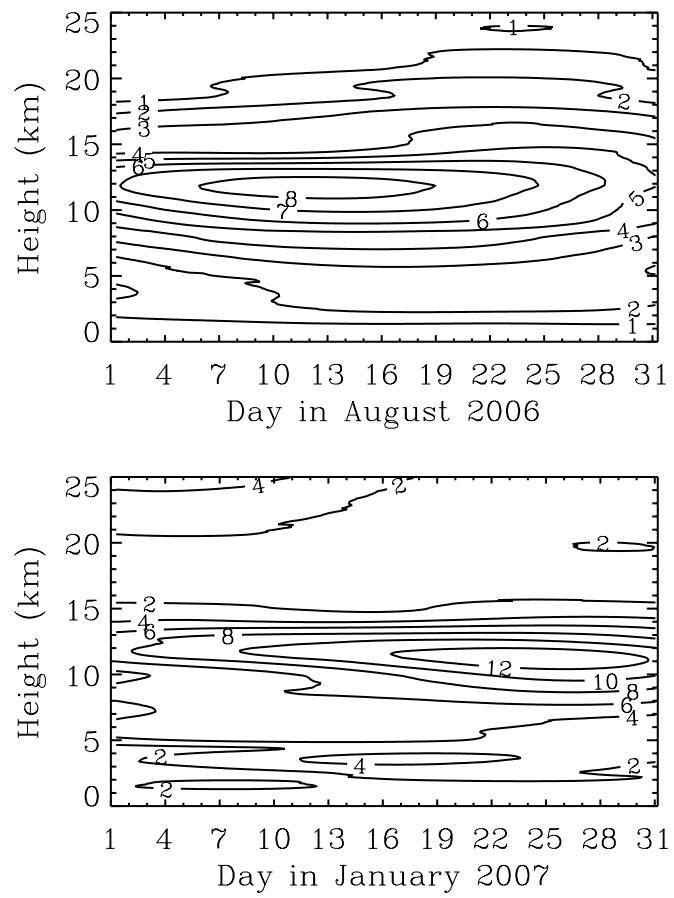

Fig. 12. Similar to Fig. 11, but for the QTDPW amplitudes.

(antinodes) are both spaced a half vertical wavelength apart. The wave phases are the constant value $\varphi\left(\varphi+180^{\circ}\right)$ at altitudes where the factor $\cos m z$ is positive (negative). These can be easily observed from the zonal wind in the summer month. Based on the node definition, we can easily find out two adjacent nodes (at 4.15 and $17.9 \mathrm{~km}$ ) in the amplitude profile of the zonal wind in the summer month. The phases between these two nodes are quasi-constant, but a quick jump of $\sim 180^{\circ}$ at the node at $4.15 \mathrm{~km}$. The phase profile of the meridional wind in the winter month also shows a quasi-constant phase between the adjacent nodes at 2.25 and $18.9 \mathrm{~km}$. These facts support the standing wave speculation. If a standing wave appears in the vertical structure, the estimation of its vertical wavelength according to the phase variation with height is questionable. Instead, the double distance between two successive nodes or antinodes would be the preferred estimation (Luo et al., 2002). So, the vertical wavelengths for the zonal wind in the summer and meridional wind in the winter are estimated to be 27.5 and $33.3 \mathrm{~km}$, respectively.

The resultant amplitudes and phases of the QTDPW are shown in Fig. 14. Evident fluctuations with height can also be observed from the amplitude profiles of the QTDPW and the amplitudes in the winter month are greater than those in the summer month. The summer (winter) zonal wind reaches its maximum $10.5 \mathrm{~ms}^{-1}\left(18.4 \mathrm{~ms}^{-1}\right)$ at $11.85 \mathrm{~km}(11.05 \mathrm{~km})$ while the summer (winter) meridional wind reaches its maximum $6.5 \mathrm{~ms}^{-1}\left(9.6 \mathrm{~ms}^{-1}\right)$ at $11.35 \mathrm{~km}(9.0 \mathrm{~km})$. Unlike that for the QSDPW, the altitudes where the QTDPW horizontal
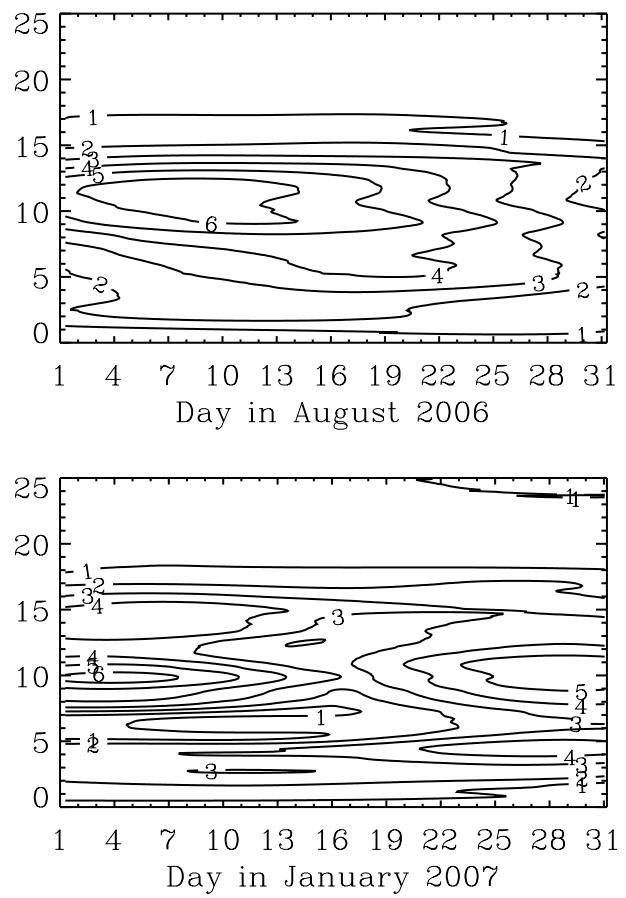

winds have significant amplitudes in the summer month are very close to those in the winter month. In the zonal wind, the phases at the altitudes where the significant wind amplitudes occur both in the summer and winter month, exhibit upward wave energy propagations, and the vertical wavelengths are both about $52 \mathrm{~km}$, almost equal to each other. In the meridional wind, the phases at the altitudes where the significant wind amplitudes occur in the summer month, exhibit upward wave energy propagations, and the vertical wavelength are about $54 \mathrm{~km}$. The standing wave feature can be readily seen from the meridional wind in the winter: the phases in the heights of 3-15 km are quasi-constant.

Both for the QSDPW and QTDPW, the wind amplitudes are all very weak near the tropopause, indicating there exists strong wave dissipation, which is consistent with the weak diurnal tide here (referring to Figs. 6 and 7). Generally speaking, the QSDPW shows the characteristics of standing waves, while the QTDPW displays those of traveling waves.

\section{PW/diurnal tide coupling}

Many investigations (Teitelbaum and Vial, 1991; Hall et al., 1995; Mitchell et al., 1996; Beard et al., 1997, 1999, 2001; Mayr et al., 2005a, b) have verified that there indeed exists coupling between PWs and tides. The generation of secondary waves and the modulated tide by PWs are usually taken as two indications for the PW/tide coupling. The frequencies of waves generated by nonlinear interactions 

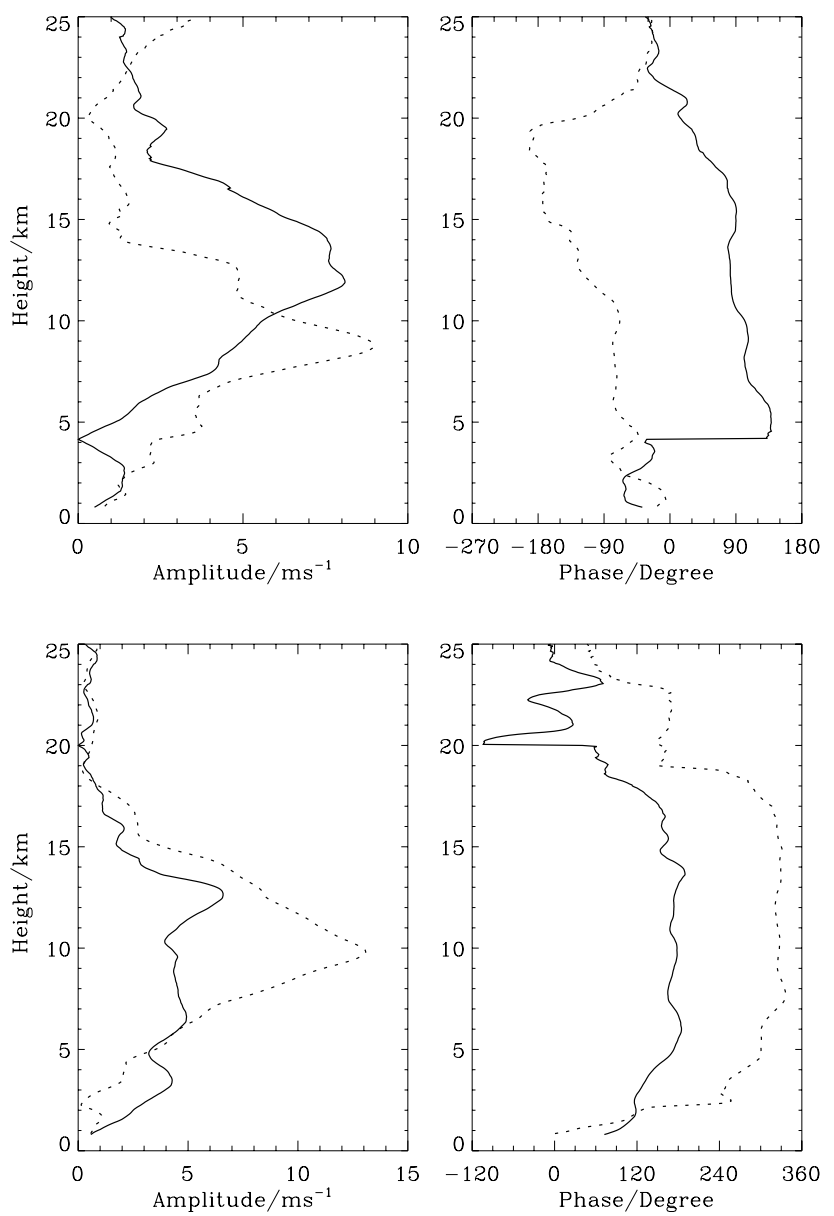

Fig. 13. The fitted amplitudes (left) and phases (right) of the QSDPW in August 2006 (solid) and January 2007 (dotted) in zonal wind (upper) and meridional wind (lower).

between the tides and PWs are the sum and/or difference of those of the primary tide and PW, i.e.

$\frac{1}{T_{g}}=\frac{1}{T_{d}} \pm \frac{1}{T_{p}}$

where, $T_{g}, T_{d}$, and $T_{p}$ are the periods of the generated waves, diurnal tide, and PW, respectively. Since the period of the $\mathrm{PW}$ is comparatively longer than that of the tide, the periods of the generated waves may be very close to that of the tide.

The spectral peaks of secondary waves at the two sideband periods can be found from Figs. 4 and 5. Since the strength of the wave-wave interaction depends on the amplitudes of the primary waves, we provide the normalized Lomb-Scargle periodograms of the high-pass filtered horizontal wind disturbances at certain heights, e.g. 14.1 and $20.2(14.1) \mathrm{km}$ for the zonal (meridional) wind in summer while $7.3(9.0) \mathrm{km}$ for the zonal (meridional) wind in winter, where the diurnal tide is relatively strong. Figure 15 is the result of the zonal and meridional wind disturbance in August 2006. For the zonal wind at $14.1 \mathrm{~km}$, around the diurnal oscillation, two sideband
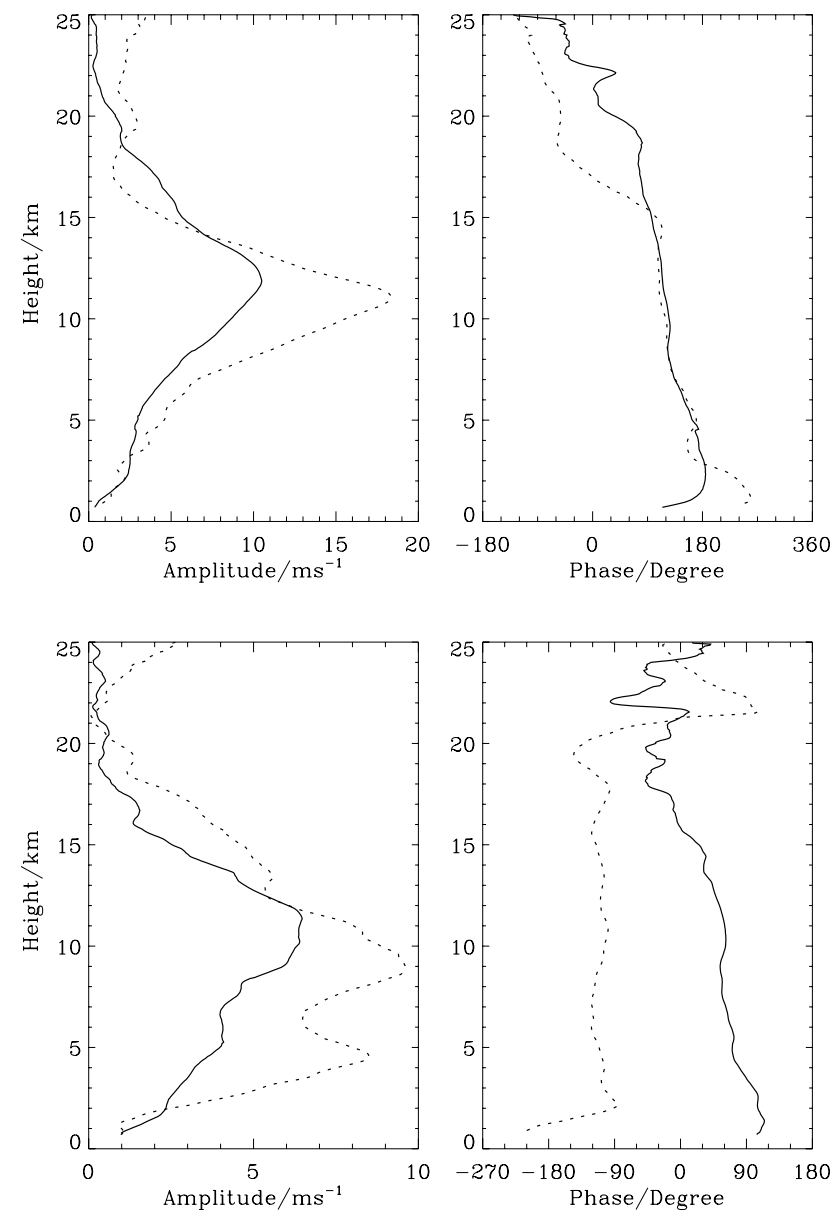

Fig. 14. Similar to Fig. 13, but for QTDPW.

waves with periods of 0.88 and 1.15 days can be recognized unambiguously (confidence levels greater than 95\%), which might be the secondary waves generated by the interaction between the diurnal tide and QSDPW, whose exact period calculated from Eq. (1) is 7.5 days. Similarly, for the zonal wind at $20.2 \mathrm{~km}$, two sideband waves with periods of 0.92 and 1.10 days can also be definitely distinguished, which may be the subsequence of the interaction between the diurnal tide and QTDPW (the calculated period is 11.0 days). It is noted that the above calculated PW periods from Eq. (1) are very close to those of QSDPW and QTDPW presented in Sect. 4. While for the meridional wind at $14.1 \mathrm{~km}$, four sideband waves, probably the generated waves by the simultaneous tide/QSDPW and tide/QTDPW interactions can be clearly seen and the calculated periods for the QSDPW and QTDPW are 6.5 and 12.0 days, respectively.

In January 2007 (Fig. 16), the secondary waves can also be detected: the sideband waves with periods of 0.92 and 1.10 days at $7.3 \mathrm{~km}$ in the zonal wind may be generated from the interaction between the tide and the QTDPW and those with periods of 0.87 and 1.15 days at $9.0 \mathrm{~km}$ in the meridional wind may be generated from the interaction between the tide 

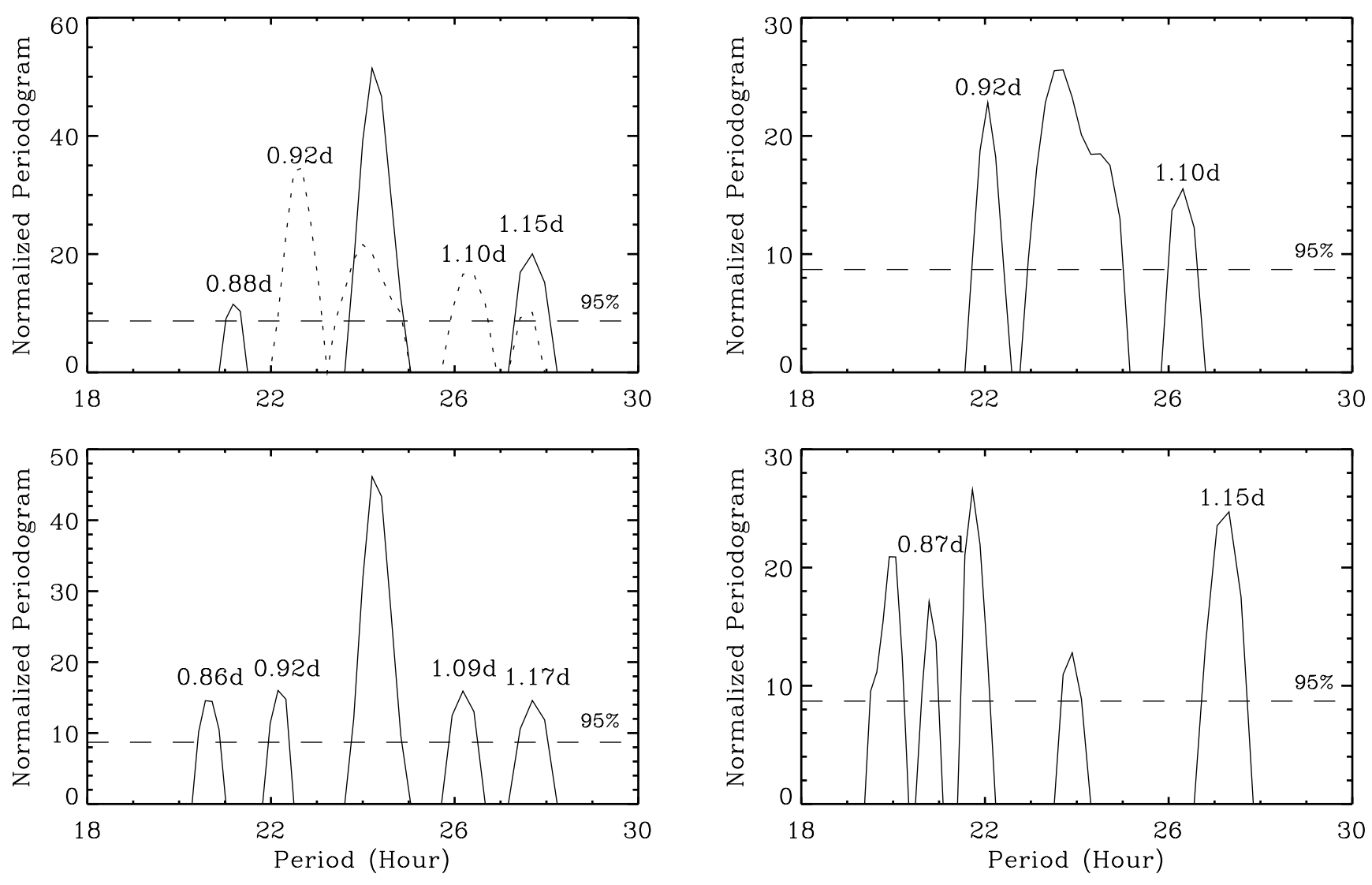

Fig. 15. Normalized Lomb-Scargle periodograms of high-pass filtered zonal wind disturbance (upper) at $14.1 \mathrm{~km}$ (solid) and $20.2 \mathrm{~km}$ (dotted), and meridional wind disturbance (lower) at $14.1 \mathrm{~km}$ in August 2006. The dashed horizontal lines denote the confidence level of $95 \%$.

and the QSDPW. Generally, the generated wave components are strong enough to be detected, which can be taken as an evidence for the nonlinear planetary/tidal wave interaction.

Besides the excitation of secondary waves, the tidal amplitude variability with periods of PWs, i.e. the modulated tide, is taken as another indication of the coupling between the tides and PWs. In order to investigate the tidal amplitude modulation by the PWs, firstly we use the detrended time series at each height to match the diurnal oscillation over a sliding 24-h window with an increment of $3 \mathrm{~h}$. So, we can get the diurnal tidal amplitudes with a 3-h interval. Then, we carry out a Lomb-Scargle periodogram analysis on the time series of the diurnal tidal amplitudes. Since the intensive quasi 10day and 7-day modulations occur around the tropopause in summer and $2-8 \mathrm{~km}$ in winter, we give the normalized periodograms of the zonal and meridional winds at $19.0 \mathrm{~km}$ in summer and at $5.0 \mathrm{~km}$ in winter in Fig. 17. Generally speaking, in both months, the quasi 7-day and 10-day spectral peaks can be found in both wind components although the exact modulation periods may be slightly different between different components (i.e. the zonal and meridional

Fig. 16. Similar to Fig. 15, but at $7.3 \mathrm{~km}$ for the zonal wind disturbance (upper) and at $9.0 \mathrm{~km}$ for the meridional wind disturbance (lower) in January 2007.

winds) and different seasons (i.e. summer and winter), e.g. 7.3 (6.8) and 11.6 (9.7) days for the zonal (meridional) wind in summer while 7.2 (7.7) and 11.6 (11.6) days for the zonal (meridional) wind in winter.

In a word, both indications for the PW/tide coupling, i.e. the generation of secondary waves and the modulated tide by the PWs, can be observed from our observations, suggesting that the coupling virtually exists in the TLS.

\section{Effects of PWs on the tropospheric jet and tropopause}

By analyzing radiosonde observations over Indonesia in spring, Tsuda et al. (1994a) have found that the 20day Kelvin wave greatly modulated the structure of the tropopause. In the following context, we would like to discuss the effects of PWs on the tropospheric jet and tropopause. Since our observation campaign covers a summer and winter month, our data can reflect the modulation effects in two seasons (i.e. summer and winter).

The tropospheric jet is known as the extremely large eastward zonal wind in the troposphere and occurs usually in winter. Here, we focus on the temporal variations of the 

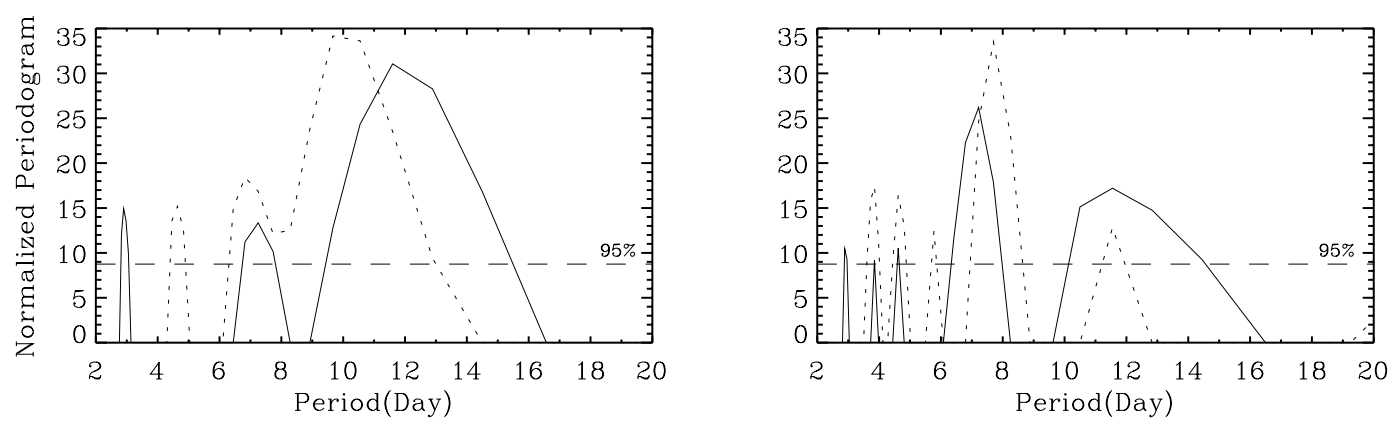

Fig. 17. Normalized Lomb-Scargle periodograms of diurnal tidal amplitudes at $19.0 \mathrm{~km}$ in August 2006 (left) and at $5.0 \mathrm{~km}$ in January 2007 (right). The solid and dotted curves denote those for the zonal and meridional wind amplitudes, respectively. The dashed horizontal lines denote the confidence level of $95 \%$.
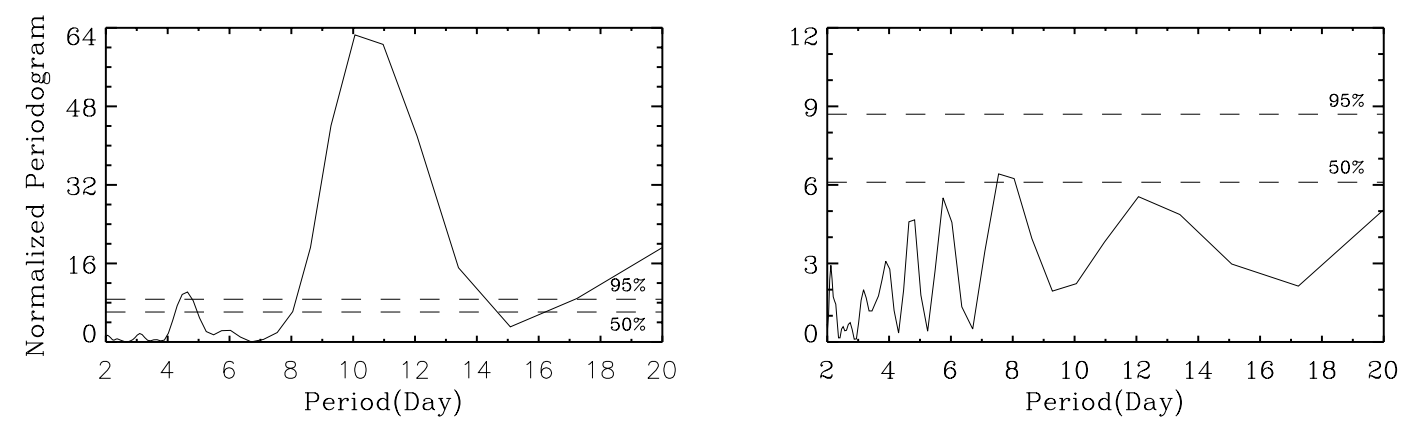

Fig. 18. Normalized Lomb-Scargle periodograms of the magnitude (left) and height (right) of the tropospheric jet in January 2007. The dashed horizontal lines denote the confidence levels of $95 \%$ and $50 \%$.

jet (defined as the maximum eastward zonal wind) and its height in January 2007, and try to find out their relations with PWs. Firstly, we identify the jet magnitude and height at every sampling time and then calculate their normalized Lomb-Scargle periodograms, which are shown in Fig. 18. It can be seen that the magnitude of the tropospheric jet has a very significant spectral peak at 10.1 days. The tropospheric jet height has two peaks located at the periods of 7.5 and 12.1 days, respectively, but their confidence levels are only about $50 \%$. We can conclude that PWs can strongly impact the magnitude of the tropospheric jet and may impact the height of the tropospheric jet to some extent.

Now we want to check if there are some links between PWs and the tropopause (defined as the minimum temperature here). Similarly, we identify the tropopause temperature and height at every sampling time at first and then calculate their normalized Lomb-Scargle periodograms, which are shown in Fig. 19. In summer (winter), the tropopause temperature has a significant peak at 11.0 (7.5) days. The tropopause height has a very significant peak with a confidence level of over $95 \%$ at 7.5 days in winter while it has a peak with a confidence level of only about $50 \%$ at 11.1 days in summer. Therefore, it is suggested that: in summer, the QTDPW can exert distinct influences on the tropopause temperature and likely influences on the tropopause height, while the QSDPW strongly impacts the tropopause temperature and height in winter.

\section{Summary}

In August 2006 and January 2007, aiming at investigating the lower atmospheric dynamics, we launched an intensive radiosonde observation campaign at Yichang $\left(111^{\circ} 18^{\prime} \mathrm{E}\right.$, $30^{\circ} 42^{\prime} \mathrm{N}$ ), China. In this campaign, the radiosonde observations were made on an eight-times-daily basis at 01:00, 04:00, 07:00, 10:00, 13:00, 16:00, 19:00 and 22:00 LT. By using the data from this campaign, in this paper we studied the primary features of the diurnal tide and PWs in the TLS over Yichang. The main results of this paper are summarized as follows:

By using a Lomb-Scargle periodogram analysis, we find that there exists dominant diurnal oscillations in the TLS over Yichang, which have seldom been reported in the midlatitudes. Generally speaking, the observational diurnal tidal amplitude and the phase are closer to the GSWM-02 than to the GSWM-00, indicating the significant contribution of nonmigrating diurnal tide, which may be owing to the local latent heat release. Since the nonmigrating tides are usually composed by high order modes with smaller vertical 

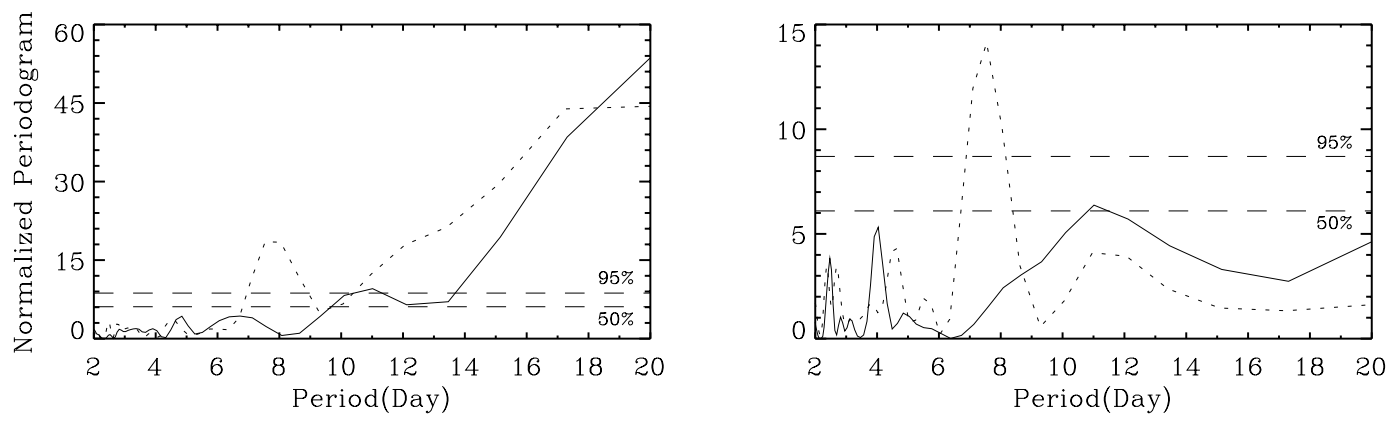

Fig. 19. Normalized Lomb-Scargle periodograms of the magnitude (left) and height (right) of the tropopause in August 2006 (solid) and January 2007 (dotted). The dashed horizontal lines denote the confidence levels of $95 \%$ and $50 \%$.

wavelengths, which are prone to dissipation in comparison to the low order modes, the observational tidal amplitudes display intensive height variations and decrease sharply at several heights.

The observational amplitudes are usually greater than those of the GSWM-02. And, according to the phase profiles of the horizontal wind components, the diurnal tidal sources are estimated to be at $13.5 \mathrm{~km}$ and $17 \mathrm{~km}$ in the summer and winter months, respectively, which are higher than the predictions from the GSWM-02. Moreover, above the source heights, the observed vertical wavelengths of the diurnal tide are smaller than those from the model due to the superposition of the nonmigrating components. These discrepancies between the observations and the GSWM-02 may result mainly from the inaccurate prediction of the nonmigrating components by the GSWM-02.

Evident seasonal differences of the diurnal tide are revealed by our observations. Compared with those in the summer month, the significant values in the horizontal winds have a smaller height coverage in the winter month. Moreover, the winter wind phase profiles indicate shorter vertical scales, which may be explained by a greater fraction of the high order tidal modes in winter. The evident seasonal differences of the water vapor mixing ratio disturbance and the tropospheric jet induced turbulence may be responsible for these seasonal differences.

Obvious quasi 7-day PW (QSDPW) and quasi 10-day PW (QTDPW) are recognized from our observations in both the summer and winter months by both the Lomb-Scargle periodogram analysis and the wavelet analysis, although the exact periods for different components (zonal and meridional winds) and in different months (August 2006 and January 2007) are not completely identical. It should be noted that: the wavelete analysis is indeed helpful to display the temporal variations of the PWs, however, because the observational duration is only one month, the exact persistence periods of the PWs can not be revealed. Both the QSDPW and QTDPW amplitudes in the winter month are greater than those in the summer month. The QSDPWs in the troposphere in both the summer and winter months show a standing wave structure, and their vertical wavelengths are about $30 \mathrm{~km}$. The QTDPWs in our observations generally exhibit traveling wave characteristics, and their vertical wavelengths are estimated to be $52 \mathrm{~km}$ for the zonal wind in both months and $54 \mathrm{~km}$ for the meridional wind in the summer month.

Spectral analyses reveal that at several heights, where the diurnal tide has relatively large amplitude, some spectral components with periods around that of the diurnal tide and satisfying the matching condition of the diurnal tide/QSDPW and diurnal tide/QTDPW interactions are identified. Additionally, the diurnal tidal amplitudes are found to be obviously modulated by the QSDPW and QTDPW. These manifest the extensive coupling between the diurnal tide and PWs in the TLS.

Tsuda et al. (1994a) have found that the 20-day wave greatly modulated the structure of the tropopause in the equatorial regions. Whereas, the relative studies in the midlatitudes have seldom been reported. We find from our observations that the PWs can strongly impact the tropospheric jet magnitude and may impact the jet height to some extent. Similar impacts of the PWs on the tropopause are also found: in summer, the QTDPW can exert distinct influences on the tropopause temperature and likely influences on the tropopause height, while the QSDPW strongly impacts the tropopause temperature and height in winter.

Acknowledgements. The authors would like to thank the anonymous reviewers for their comments on the manuscript. This work was jointly supported by the National Natural Science Foundation of China (through grant 40825013, 40774084, and 40731055), the Program for Changjiang Scholars and Innovative Research Team in University (PCSIRT), the Program of China Meteorological Administration (Grant No. GYHY200706013), and the Open Foundation of State Key Laboratory of Space Weather.

Topical Editor U.-P. Hoppe thanks two anonymous referees for their help in evaluating this paper. 


\section{References}

Alexander, M. J.: Interpretations of observed climatological patterns stratospheric gravity wave variance, J. Geophys. Res., 103, 8627-8640, 1998.

Alexander, M. J. and Pfister, L.: Gravity wave momentum flux in the lower stratosphere over convection, Geophys. Res. Lett., 22, 2029-2032, 1995.

Allen, S. J. and Vincent, R. A.: Gravity-wave activity in the lower atmosphere: Seasonal and latitudinal variations, J. Geophys. Res., 100, 1327-1350, 1995.

Batista, P. P., Clemesha, B. R., Tokumoto, A. S., and Lima, L. M.: Structure of the mean winds and tides in the meteor region over Cachoeira Paulista, Brazil $\left(22.7^{\circ} \mathrm{S}, 45^{\circ} \mathrm{W}\right)$ and its comparison with models, J. Atmos. Sol.-Terr. Phys., 66, 623-636, 2004.

Beard, A. G., Mitchell, N. J., Williams, P. J. S., Jones, W., and Muller, H. G.: Mesopause region tidal variability observed by meteor radar, Adv. Space Res., 20, 1237-1240, 1997.

Beard, A. G., Mitchell, N. J., Williams, P. J. S., and Kunitake, M.: Nonlinear interactions between tides and planetary waves resulting in periodic tidal variability, J. Atmos. Sol.-Terr. Phys., 61, 363-376, 1999.

Beard, A. G., Williams, P. J. S., Mitchell, N. J., and Muller, H. G.: A spectral climatology of planetary waves and tidal variability, J. Atmos. Solar-Terr. Phys., 63, 801-811, 2001.

Forbes, J. M. and Leveroni, S.: Quasi 16-day oscillation in the ionosphere, Geophys. Res. Lett., 19, 981-984, 1992.

Forbes, J. M., Hagan, M. E., Zhang, X., and Hamilton, K.: Upper atmosphere tidal oscillations due to latent heat release in the tropical troposphere, Ann. Geophys., 15, 1165-1175, 1997, http://www.ann-geophys.net/15/1165/1997/.

Fritts, D. C. and Alexander, M. J.: Gravity wave dynamics and effects in the middle atmosphere, Rev. Geophys., 41, 1003, doi:10.1029/2001RG000106, 2003.

Hagan, M. E., Roble, R. G., and Hackney, J.: Migrating thermospheric tides, J. Geophys. Res., 106, 12739-12752, 2001.

Hagan, M. E. and Forbes, J. M.: Migrating and nonmigrating diurnal tides in the middle and upper atmosphere excited by tropospheric latent heat release, J. Geophys. Res., 107, 4754, doi:10.1029/2001JD001236, 2002.

Hall, G. E., Namboothiri, S. P., Manson, A. H., and Meek, C. E.: Daily tidal, planetary wave, and gravity wave amplitudes over the Canadian prairies, J. Atmos. Terr. Phys., 13, 1553-1567, 1995.

Hirota, I. and Hirooka, T.: Normal mode Rossby waves observed in the upper stratosphere, part I: First symmetric modes of zonal wavenumbers 1 and 2, J. Atmos. Sci., 41, 1253-1267, 1984.

Hirooka, T. and Hirota, I.: Normal mode Rossby waves observed in the upper stratosphere, Part II: Second antisymmetric and symmetric modes of zonal wavenumbers 1 and 2, J. Atmos. Sci., 42, 536-548, 1985.

Hong, S.-S. and Wang, P.-H.: On the thermal excitation of atmospheric tides, B. Geophys. Natl. Cent. Univ. Taiwan, 19, 56-83, 1980.

Innis, J. L., Klekociuk, A. R., and Vincent, R. A.: Interstation correlation of high-latitude lower-stratosphere gravity wave activity: Evidence for planetary wave modulation of gravity wave over Antarctica, J. Geophys. Res., 109, D17106, doi:10.1029/2004JD004961, 2004.

Kishore, P., Namboothiri, S. P., Igarashi, K., Gurubaran, S., Sridharan, S., Rajaram, R., and Ratnam, M. V.: MF radar observations of 6.5-day wave in the equatorial mesosphere and lower thermosphere, J. Atmos. Sol.-Terr. Phys., 66, 507-515, 2004.

Lawrence, A. and Jarvis, M. J.: Simultaneous observations of planetary waves from 30 to $220 \mathrm{~km}$, J. Atmos. Sol.-Terr. Phys., 65, 765-777, 2003.

Lindzen, R. S.: Effect of daily variations of cumulonimbus activity on the atmospheric semidiurnal tide, Mon. Weather Rev., 106, 526-533, 1978.

Lu, X., Zhang, S. D., and Yi, F.: Radiosonde observation of planetary waves in the lower atmosphere over central China, Chin. J. Space Sci., 25, 529-535, 2005.

Luo, Y., Manson, A. H., Meek, C. E., Thayaparan, T., MacDougall, J., and Hocking, W. K.: The 16-day wave in the mesosphere and lower thermosphere: simultaneous observations at Saskatoon $\left(52^{\circ} \mathrm{N}, 107^{\circ} \mathrm{W}\right)$ and London $\left(43^{\circ} \mathrm{N}, 81^{\circ} \mathrm{W}\right)$, Canada, J. Atmos. Sol.-Terr. Phys., 64, 1287-1307, 2002.

Manson, A. H., Luo, Y., and Meek, C.: Global distributions of diurnal and semi-diurnal tides: observations from HRDI-UARS of the MLT region, Ann. Geophys., 20, 1877-1890, 2002, http://www.ann-geophys.net/20/1877/2002/.

Mayr, H. G., Mengel, J. G., Talaat, E. R., Porter, H. S., and Chan, K. L.: Mesospheric non-migrating tides generated with planetary waves: I. Characteristics, J. Atmos. Sol.-Terr. Phys., 67, 959980, 2005a.

Mayr, H. G., Mengel, J. G., Talaat, E. R., Porter, H. S., and Chan, K. L.: Mesospheric non-migrating tides generated with planetary waves: II. Influence of gravity waves, J. Atmos. Sol.-Terr. Phys., 67, 981-991, 2005b.

Mitchell, N. J., Williams, P. J. S., Beard, A. G., Buesnel, G. R., and Muller, H. G.: Non-linear planetary/tidal wave interactions in the lower thermosphere observed by meteor radar, Ann. Geophys., 19, 364-366, 1996, http://www.ann-geophys.net/19/364/1996/.

Pfenninger, M. A., Liu, A. Z., Papen, G. C., and Gardner, C. S.: Gravity wave characteristics in the lower atmosphere at South Pole, J. Geophys. Res., 104, 5963-5984, 1999.

Randel, W. J., Stevens, D. E., and Stanford, J. L.: A study of planetary waves in the southern winter troposphere and stratosphere, part II: Life cycles, J. Atmos. Sci., 44, 936-949, 1987.

Salby, M. L.: Survey of planetary-scale traveling waves: The state of theory and observations, Rev. Geophys. Space Phys., 22, 209236, 1984.

Seidel, D. J., Free, M., and Wang, J.: Diurnal cycle of upper-air temperature estimated from radiosondes, J. Geophys. Res, 110, D09102, doi:10.1029/2004JD005526, 2005.

Scargle, J. D.: Studies in astronomical time series analysis, II Statistical aspects of spectral analysis of unevenly spaced data, Astrophysical J., 263, 835-853, 1982.

Shepherd, M. and Fricke-Begemann, C.: Study of the tidal variations in mesospheric temperature at low and mid latitudes from WINDII and potassium lidar observations, Ann. Geophys., 22, 1513-1528, 2004, http://www.ann-geophys.net/22/1513/2004/.

Shimizu, A. and Tsuda, T.: Characteristics of Kelvin waves and gravity waves observed with radiosondes over Indonesia, J. Geophys. Res., 102, 26159-26171, 1997.

Smith, A. K.: Stationary planetary waves in upper mesospheric winds, J. Atmos. Sci., 54, 2129-2145, 1997.

Teitelbaum, H. and Vial, F.: On tidal variability induced by non- 
linear interaction with planetary waves, J. Geophys. Res., 96, 14179-14182, 1991.

Tsuda, T., Murayama, Y., Wiryosumarto, H., Harijono, S. W. B., and Kato, S.: Radiosonde observations of equatorial atmosphere dynamics over Indonesia, 1, Equatorial waves and diurnal tides, J. Geophys. Res., 99, 10491-10505, 1994a.

Tsuda, T., Murayama, Y., Wiryosumarto, H., Harijono, S. W. B., and Kato, S.: Radiosonde observations of equatorial atmosphere dynamics over Indonesia, 2, Characteristics of gravity waves, J. Geophys. Res., 99, 10506-10516, 1994b.

Tusda, T., Nakamura, T., Shimizu, A., Yoshino, T., Harijono, S. W. B., Sribimawati, T., and Wiryosumarto, H.: Observations of diurnal oscillations with a meteor wind radar and radiosondes in Indonesia, J. Geophys. Res., 102, 26217-26224, 1997.

Vincent, R. A.: Planetary and gravity waves in the mesosphere and lower thermosphere, Adv. Space Res., 10, 93-101, 1990.

Vincent, R. A. and Alexander, M. J.: Gravity waves in the tropical lower stratosphere: An observational study of seasonal and interannual variability, J. Geophys. Res., 105, 17971-17982, 2000.

Vincent, R. A., Kovalam, S., Fritts, D. C., and Isler, J. R.: Longterm MF radar observations of solar tides in the low-latitude mesosphere: Interannual variability and comparisons with the GSWM, J. Geophys. Res., 103, 8667-8683, 1998.

Wang L., Geller, M. A., and Alexander, M. J.: Spatial and temporal variations of gravity wave parameters, Part I: Intrinsic frequency, wavelength, and vertical propagation direction, J. Atmos. Sci., 62, 125-142, 2005.

Williams, C. R. and Avery, S. K.: Analysis of long-period waves using the mesosphere-stratosphere- troposphere radar at Poker Flat, Alaska, J. Geophys. Res., 97, 20855-20861, 1992.

Yi, F.: Short-term variability and temporary structures of tides and mean wind in the polar summer mesosphere, J. Atmos. Sol.-Terr. Phys., 63, 749-757, 2001.

Yoshiki, M. and Sato, K.: A statistical study of gravity waves in the polar regions based on operational radiosonde data, J. Geophys. Res., 105, 17995-18011, 2000.
Zhang, S. D., Yi, F., and Hu, X.: MF radar observation of mean wind and tides of winter mesopause $(80-98 \mathrm{~km})$ region over Wuhan $\left(30^{\circ} \mathrm{N}-114^{\circ} \mathrm{E}\right)$, J. Atmos. Sol.-Terr. Phys., 66, 15-25, 2004.

Zhang, S. D. and Yi, F.: A statistical study of gravity waves from radiosonde observations at Wuhan $\left(30^{\circ} \mathrm{N}, 114^{\circ} \mathrm{E}\right)$, China, Ann., Geophys., 23, 665-673, 2005.

Zhang, S. D., Huang, C. M., and Yi, F.: Radiosonde observations of vertical wave number spectra for gravity waves in the lower atmosphere over Central China, Ann. Geophys., 24, 3257-3265, 2006, http://www.ann-geophys.net/24/3257/2006/.

Zhang, S. D. and Yi, F.: Latitudinal and seasonal variations of inertial gravity wave activity in the lower atmosphere over central China, J. Geophys. Res., 112, D05109, doi:10.1029/2006JD007487, 2007

Zhang, S. D., Yi, F., Huang, C. M., and Chen, Z. Y.: Intensive radiosonde observations of gravity waves in the lower atmosphere over Yichang $\left(111^{\circ} 18^{\prime} \mathrm{E}, 30^{\circ} 42^{\prime} \mathrm{N}\right)$, China, Ann. Geophys., 26, 2005-2018, 2008, http://www.ann-geophys.net/26/2005/2008/.

Zhang, Y. H., Zhang, S. D., and Yi, F.: Intensive radiosonde observations of lower tropospheric inversion layers over Yichang, China, J. Atmos. Sol.-Terr. Phys., 71, 180-190, 2009.

Zink, F. and Vincent, R. A.: Wavelet analysis of stratospheric gravity wave packets over Macquarie Island, 1. Wave parameters, J. Geophys. Res., 106, 10275-10288, 2001a.

Zink, F. and Vincent, R. A.: Wavelet analysis of stratospheric gravity wave packets over Macquarie Island, 2. Intermittency and mean-flow accelerations, J. Geophys. Res., 106, 10289-10297, 2001b. 